\title{
Statistical Analysis of Natural Water Conductivity Data Behavior in Two Wells: Seismic Coastal Border Limits of Guerrero-Oaxaca States, Mexico
}

\author{
Fidel Martínez-García \\ Center of Proposed Draft of the South Pacific, Federal Electricity Commission, Cuernavaca, Morelos, Mexico \\ Email: fmg1376@yahoo.com.mx
}

How to cite this paper: Martínez-García, F. (2017) Statistical Analysis of Natural Water Conductivity Data Behavior in Two Wells: Seismic Coastal Border Limits of Guerrero-Oaxaca States, Mexico. Open Access Library Journal, 4: e3900. https://doi.org/10.4236/oalib.1103900

Received: August 21, 2017

Accepted: September 11, 2017

Published: September 14, 2017

Copyright $\odot 2017$ by author and Open Access Library Inc.

This work is licensed under the Creative Commons Attribution International License (CC BY 4.0).

http://creativecommons.org/licenses/by/4.0/ (c) (i) Open Access

\begin{abstract}
In this document, with the purpose of strengthening more in the knowledge of the previous events on the earthquakes, the possible connection between natural voltage and electromagnetic energy emanating from the inner layers of the Earth and the seismic activity in the Mexican seismic coastal border, is evaluated, through an indirect estimation of the statistical analysis of natural water conductivity data $(\mu \mathrm{S} / \mathrm{cm})$ and the seismic activity occurred in the same period within continental and marine environment, monitored intensively from February 2 to April 15, 2015 and from May 11 to July 17, 2015 in two ordinary man-made wells. A total 128,469 water conductivity data with a sampling frequency of 45 seconds, confronted with 950 earthquakes occurred in the same periods to distance range of 50,100,150,200, 250, 300, 350 and 400 kilometers far away from a conductivity sensor, are analyzed. As results, in the range of 50 kilometers round the conductivity sensor, the study area applied demonstrates to be a location where the major quantity of earthquakes and most atypical conductivity variations occurred. The influence of the local environment on the behavior of the conductivity data is debated according to the geographical position of the conductivity sensor. Within the continental environment, the range of 0 to $50 \mathrm{~km}$ showed the most important statistical significance, revealing to have the most number of earthquakes, with higher values and more intensity, particularly when the trend of conductivity data is descending. Within the marine environment, a very similar connection between the conductivity data behavior and seismic activity occurred was observed.
\end{abstract}

\section{Subject Areas}

Geophysics 


\section{Keywords}

Natural Water Conductivity, Earthquakes Precursor Events, Electromagnetic Energy, Electromagnetic Emission (EME)

\section{Introduction}

This document involved the statistical analysis of natural water conductivity data $(\mu \mathrm{S} / \mathrm{cm})$ within the Mexican seismic coastal border with the purpose of contributing to the knowledge of the phenomena related to the precursor events of earthquakes. In this context, the possible connection between natural voltage and electromagnetic energy emanating from the Earth's interior and the seismic activity in that region is evaluated.

The study of the electromagnetic energy related with the seismic activity, regularly has been addressed through evaluations of electromagnetic emission (EME) in the range of very, ultra-low and extremely low-frequency waves that reach the Earth surface through faults or unstable areas. This kind of radiation manifest their influence changing the local atmospheric electricity in the local ionosphere, and the activity level sometimes increases one week just before to an earthquake event, although with micro-seismic activity ( $<4-4.5$ degrees), this kind of anomalies are monitored with the use of ground-based observations or remote sensing with satellite with the objective of detect plasma perturbations, thermal anomalies and radio emissions associated with EQs in the local atmosphere [1]-[8]; with the atmospheric electricity changes occur heating and increasing the local relative humidity [9] [10] [11] [12], changes that produce or leads occasionally to local luminous phenomena or earthquake lights (EQL), phenomenon commonly observed few weeks or hours before an earthquake, sometimes appears diffused light looking as reddish light ranging from orange to violet, others are halos having a dull rose colored luminosity, sky yellow light like an aurora or vapor with limited luminosity covering the local mountains, generally low-lying, just meters above the ground [13] [14] [15] [16]. The EME also influences the formation of aerosols and clouds and the presence of positive ions immersed within a charged atmosphere. The clouds anomalies regularly before an earthquake, show linear pattern along active faults that remain for hours without no movement, affecting several kilometers but disappear a few days after the event [17]-[23]. Although recurrently debated, this EME anomalies get influence the behavior of birds, fishes, mammals and including humans: animal responses to earthquake-related stimuli are varied, sometime is related to acoustic waves at low frequency, also aquatic animals are able to perceive electrical impulses; the strange behavior of animals sometimes is attributed to the environmental presence of pre-seismic EM emissions. In the case, human being frequently feel the discomfort in the ears or general physical inconvenience in 
the whole body: irritability, dizziness, insomnia, pain in the ears and migraines [10] [11] [24]-[30].

The study of electromagnetic emissions (EME) as large earthquake short-term prediction involves very, ultra-low and extreme frequency electromagnetic emissions, and frequently this information is obtained by remote sensing. In this regard, the data more used in very studies was related to micro-satellite DEMETER (Detection of Electromagnetic Emissions Transmitted from Earthquake Regions) designed expressly for Ionosphere perturbations linked to earthquakes, man-made transmitters, volcanoes and lightning [6] [31] [32] [33] [34]; the mission satellite was retired on December 9, 2010 after more than 6.5 years on orbit (https://demeter.cnes.fr/fr/DEMETER/Fr/index.htm). Other research projects apply ground observation by mean of antennas, detectors and an analyzer system's network.

\section{Backgrounds}

As a complement of two previous studies [35] [36], in the ambit of electromagnetic emissions study (EME) possibly emanating from the Earth's interior layers, of indirect way and applying a micro-regional focus related to ground observation, from fourth trimester of 2014 it was conducted a data statistical research to evaluate these emanations, studying the possibly influence of EME on the water natural conductivity behavior and its possible relationship with earthquakes manifested during the time period of monitoring. The study area it was located on the Pacific coast of southern Mexico in a section considered the most seismic region on the coastal border in Oaxaca estate limits, this is located on the Pinotepa National municipality, particularly in a coastal community called "Corralero" [35] [36] [37] [38] [39].

The monitoring and information gathered of the natural conductivity of water evaluated in the region from September 2014 to February 2015 [35] [36], considering monitoring sites of low, moderate and high seismic activity, a research focus with no prior known antecedents until 2014. The results showed in that first step, the possible presence of patterns behavior in the data of natural conductivity, one of them pointed to the relationship existing between the geographical position of conductivity sensor and the seismic activity manifested during the monitoring period; to 290 kilometers far away from the coastal border, the presence of "atypical variations" of conductivity data (rare drops and peaks) was almost imperceptible and in the surroundings, few seismic occurred during the period of monitoring.

But within the coastal border between Guerrero and Oaxaca states, the atypical variations were self-evident and the presence of micro seismic activity was very significant $(<4.0 \mathrm{Mw})$ Figure 2 at [35]. In addition, the data analyzed of the coastal border drove to another pattern, the subtle connection with the subsequent occurrence of seismic activity and the atypical variations of conductivity data, this behavior is possibly influenced by energy emanating from inside the 
Earth's layers taking into account the possible high level of rock fracturing of the regional continental crust [37].

The second step of area analysis studied from March to July, 2016, emphasized the comparison of natural water conductivity data of two wells [36], both separated by 80 meters from each other, this focus showed other interesting patterns, one of them denoted the daily and frequent variation of natural conductivity possibly related to the internal flow of water, the groundwater movement is extremely fast indicating a vigorous groundwater recharge, possibly related to terrain compress or slight tilting of ground caused by very light earthquakes [10] [38] [39]. The analysis of multiple 24-hour data series sets showed another pattern: the noticeable oscillations of natural conductivity between 7:00 to 22:00 hours, possibly related to human activity but, this influence is not very clear and proved truthfully, Figure 11 at [36]. The last one pattern observed revealed that during the total data monitoring of conductivity through 61 days there were three significant variations of natural conductivity in different periods (May 15 to 23; May 31 to June 9 and June 15 to July 9) highlighting the last period because showed that during the water conductivity increase run-up, there was null seismic activity but when water conductivity decreased, the seismic activity increased considerably with seismic events more of them with $\mathrm{Mw}<4$, Figure 13 at [36].

\section{Method and Results}

\section{Method and Focus}

The main approach used in this document was based on the statistical analysis of the data of water natural conductivity $(\mu \mathrm{S} / \mathrm{cm})$ and its behavior trends, recorded by a conductivity sensor data-logger, and likely correspondence or correlation with subsequent seismic activity $(<4.0 \mathrm{Mw})$ occurred to distance range of 50 , $100,150,200,250,300,350$ and 400 kilometers far away of the sensor, as an indirect way to find out the possible presence of EME and its influence in the local environmental conditions, Figure 1. The data period analysis was from February 3 to April 15, 2015, at well CAW01, and from May 11 to July 17, 2015, at well CAW02, the total number of data recorded was 128,469 using a sampling frequency of 45 seconds; the reservoirs are located at the geographic coordinates $16^{\circ} 14^{\prime} 10.6^{\prime \prime} \mathrm{N}$ and $98^{\circ} 11.406^{\prime} \mathrm{W}$, and $16^{\circ} 14^{\prime} 10.5^{\prime \prime} \mathrm{N}$ and $98^{\circ} 11^{\prime} 14.5^{\prime \prime} \mathrm{W}$; their dimensions correspond to $1 \times 1 \times 6$ meters and $1.3 \times 1.3 \times 3$ meters, respectively. The technical characteristics of sensor used, correspond to a non-contact capacitive sensor commercially called Data-logger HOBO U24-001, the details of the instrument technical specification used are in [35] [36] [40]. The 950 earthquakes occurred within continental and marine environment in 2015 in the territorial limits of Guerrero and Oaxaca states, Mexico, were acquired of the page Web of the Seismological National (SSN) Service of Mexico, http://www.ssn.unam.mx/.

In order to generate some graphs displaying the interaction of natural conductivity behavior and the seismic activity manifested in such periods above 


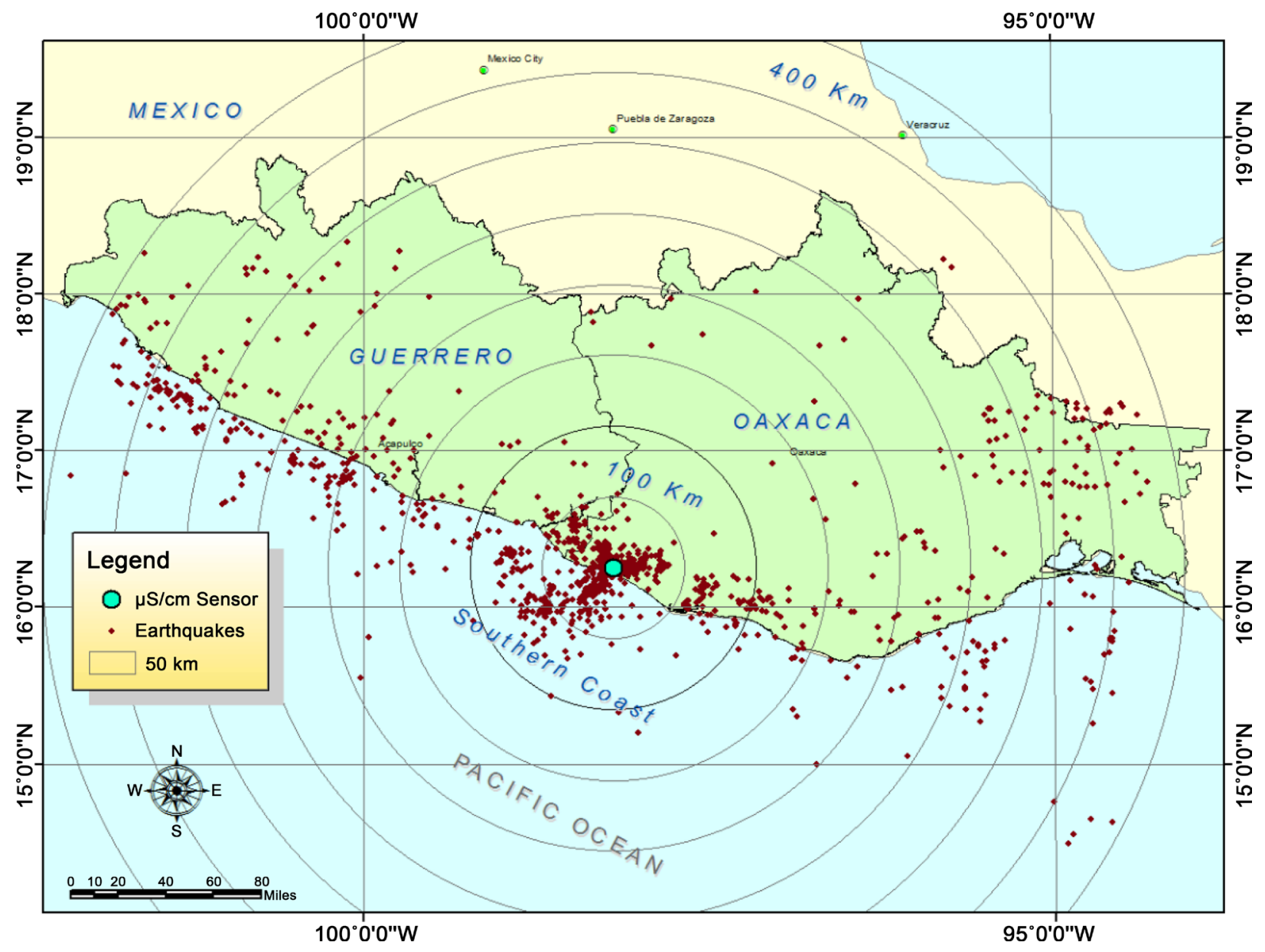

Figure 1. Conductivity sensor geographic position and earthquakes occurred a different distances.

mentioned, on average 128,469 records of natural conductivity of water and 950 earthquakes were analyzed and graphed; in complement, basics statistics such as minimum, maximum, mode and total earthquakes occurred and Fisher test, were obtained and applied.

\section{Results}

The data statistical analysis of the natural conductivity behavior were carried out in two wells separated 80 meters from each other; each well was analyzed both in their spatial position between them and at different distance ranges, considering the position of the conductivity sensor and the earthquakes occurred during the same monitoring period, Figure 1. Taking into account the distance ranges of $50,100,150,200,250,300,350,400$ and 450 kilometers, separately for each well, the interactions of measured conductivity and earthquakes manifested in both the continental and marine environments were analyzed, as result 32 graphs of both environment were obtained, Figures 2-9 and Figures 10-17 correspond to site CAW01 in the continental and marine environment respectively; Figures 18-25 and Figures 26-33 correspond to site CAW02 in the continental and environment marine in the order given. So as to find out noteworthy dif- 


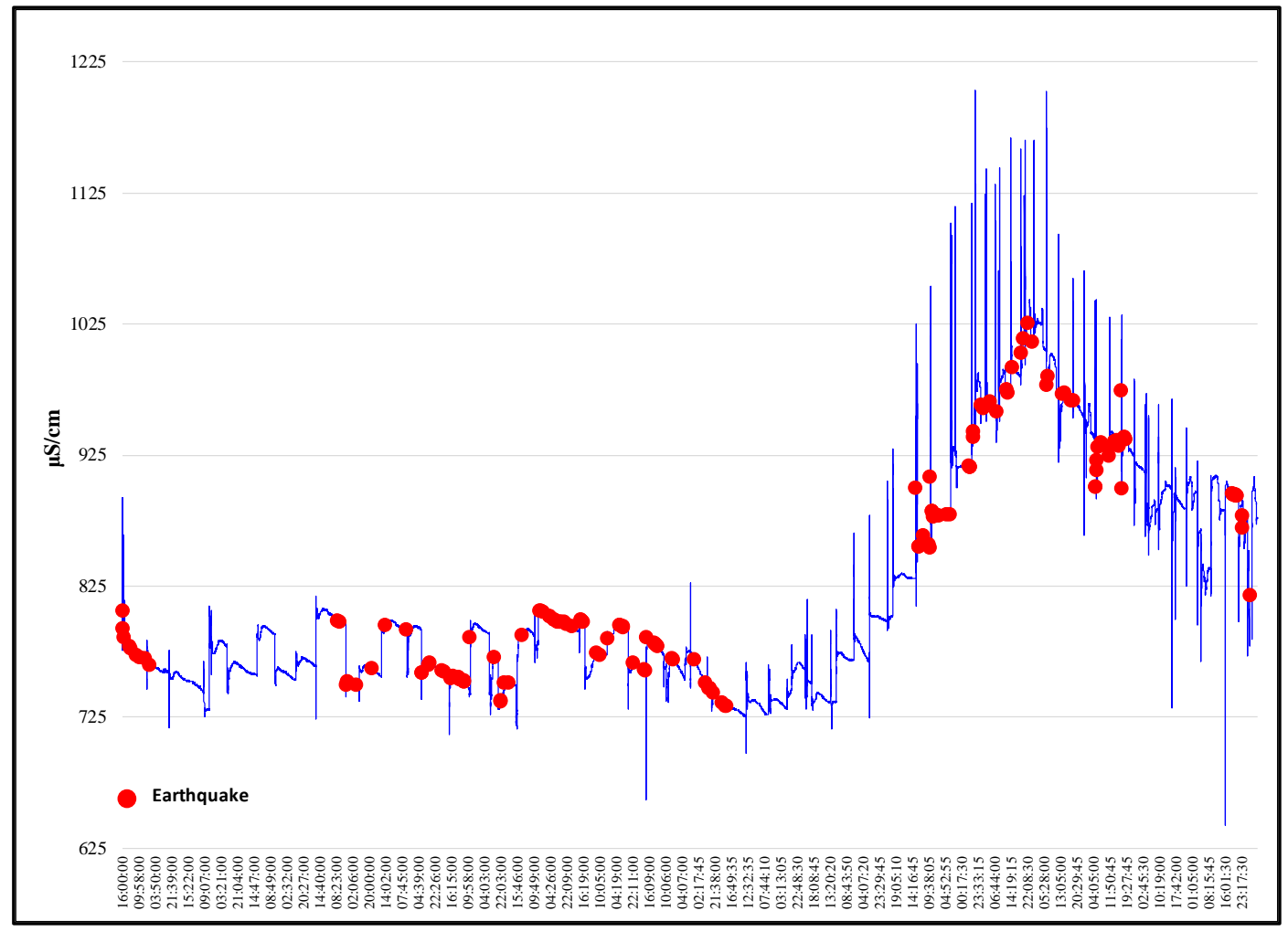

Figure 2. Site CAW01: Possible correlation between the conductivity records and earthquakes in a horizontal range of $0-50 \mathrm{~km}$ around the sensor $(\mu \mathrm{S} / \mathrm{cm})$ within the continental environment.

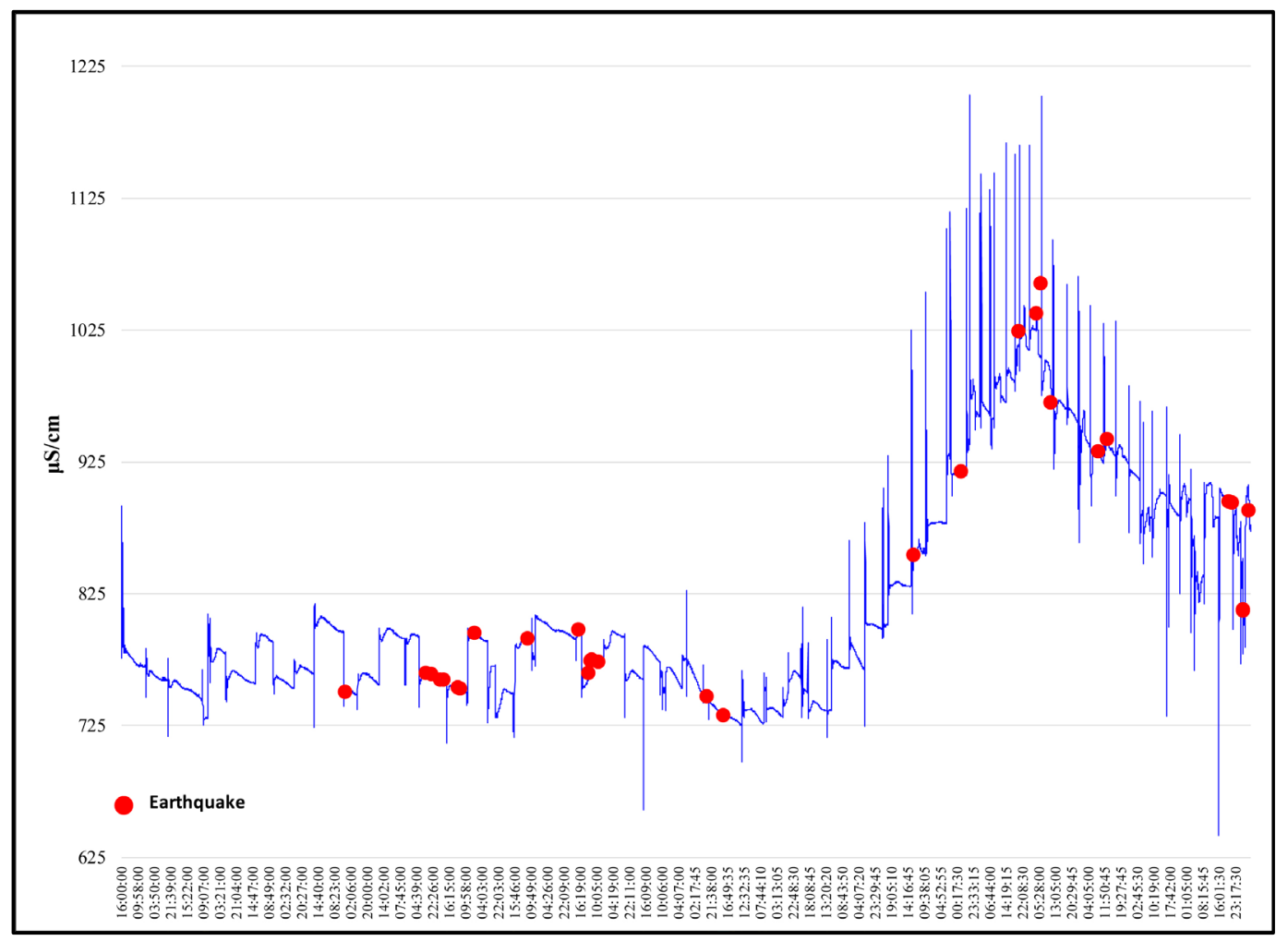

Figure 3. Site CAW01: Possible correlation between the conductivity records and earthquakes in a horizontal range of $50-100 \mathrm{~km}$ around the sensor $(\mu \mathrm{S} / \mathrm{cm})$ within the continental environment. 


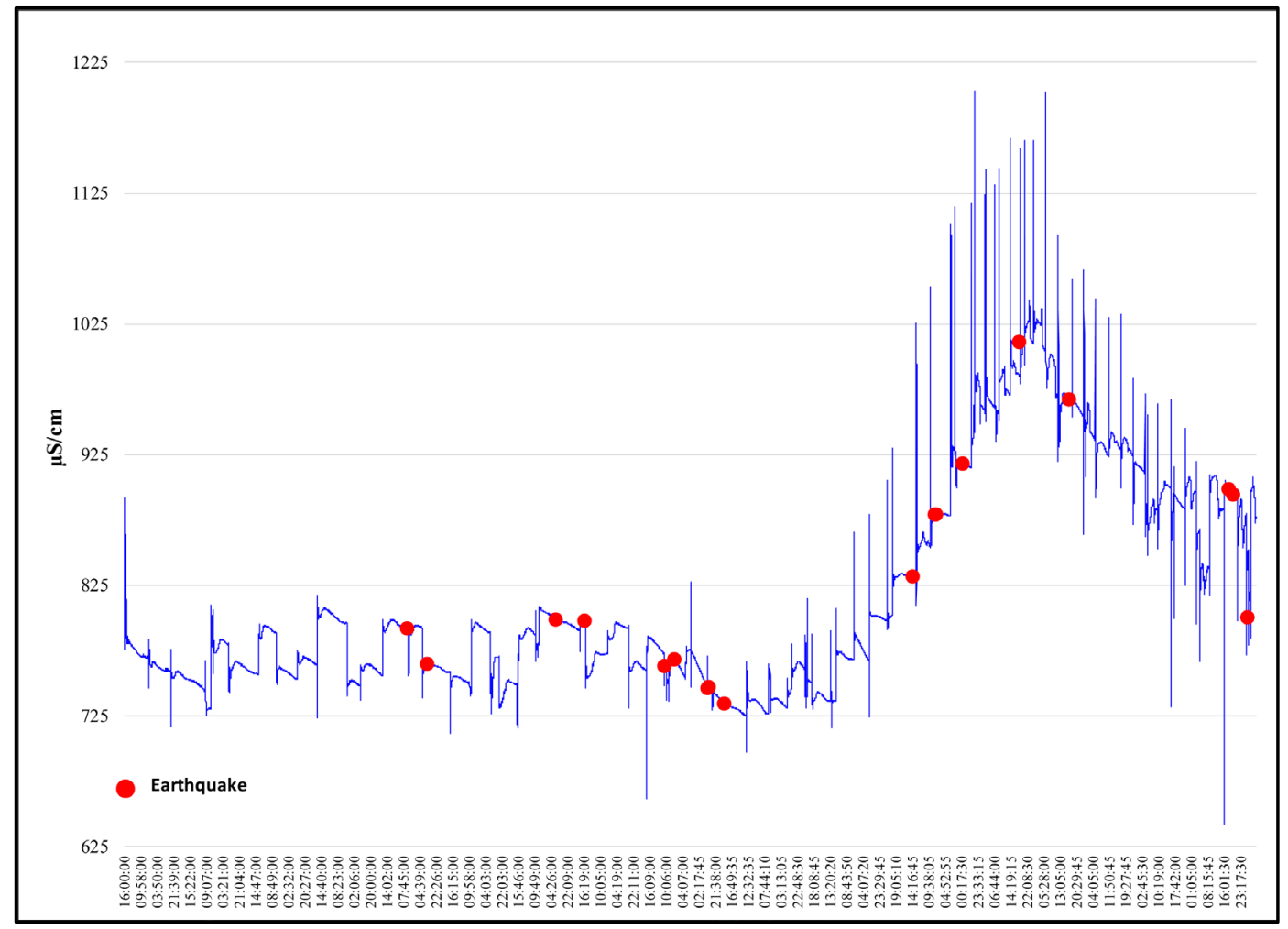

Figure 4. Site CAW01: Possible correlation between the conductivity records and earthquakes in a horizontal range of $100-150 \mathrm{~km}$ around the sensor $(\mu \mathrm{S} / \mathrm{cm})$ within the continental environment.

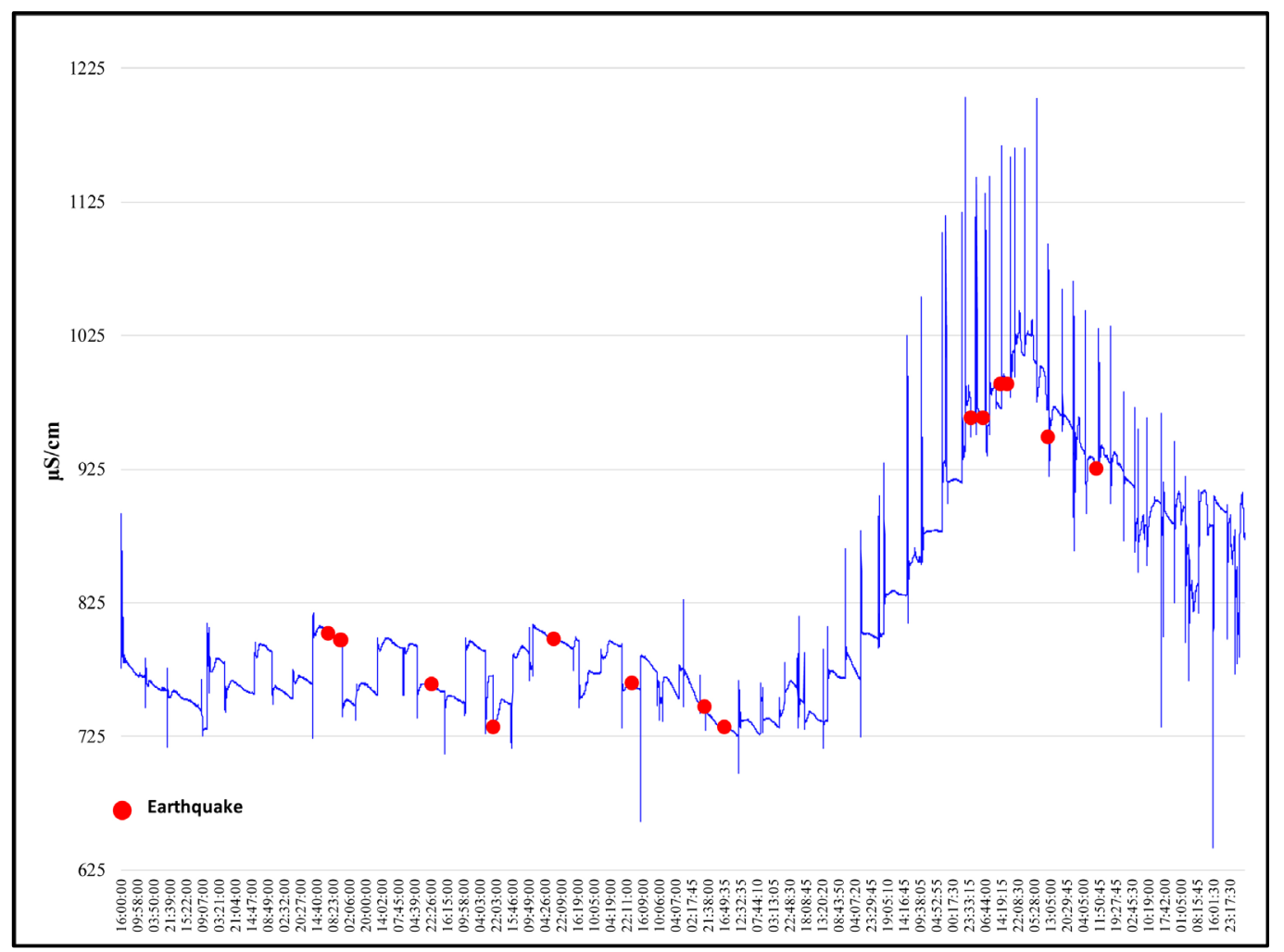

Figure 5. Site CAW01: Possible correlation between the conductivity records and earthquakes in a horizontal range of $150-200 \mathrm{~km}$ around the sensor $(\mu \mathrm{S} / \mathrm{cm})$ within the continental environment. 


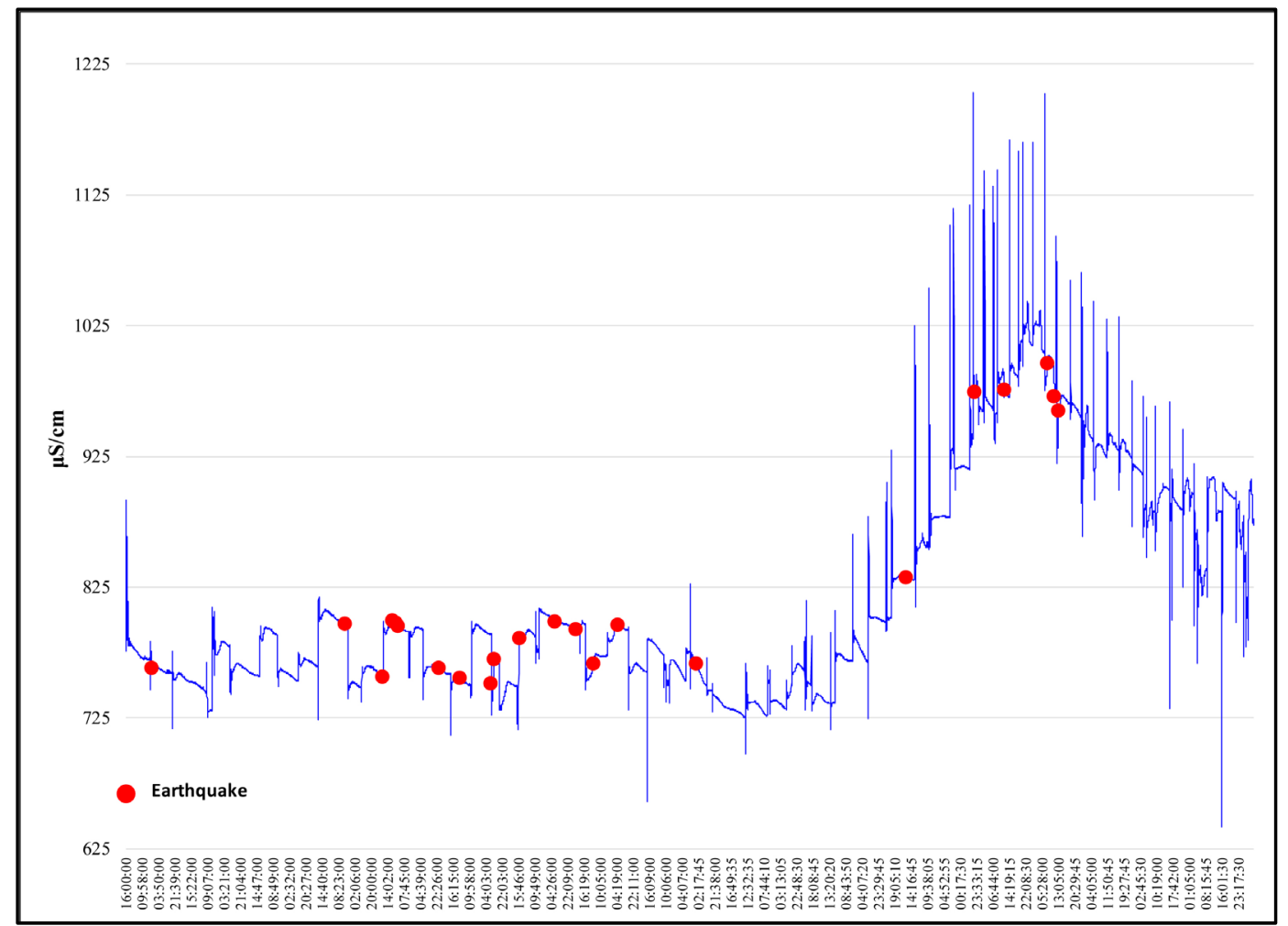

Figure 6. Site CAW01: Possible correlation between the conductivity records and earthquakes in a horizontal range of $200-250 \mathrm{~km}$ around the sensor $(\mu \mathrm{S} / \mathrm{cm})$ within the continental environment.

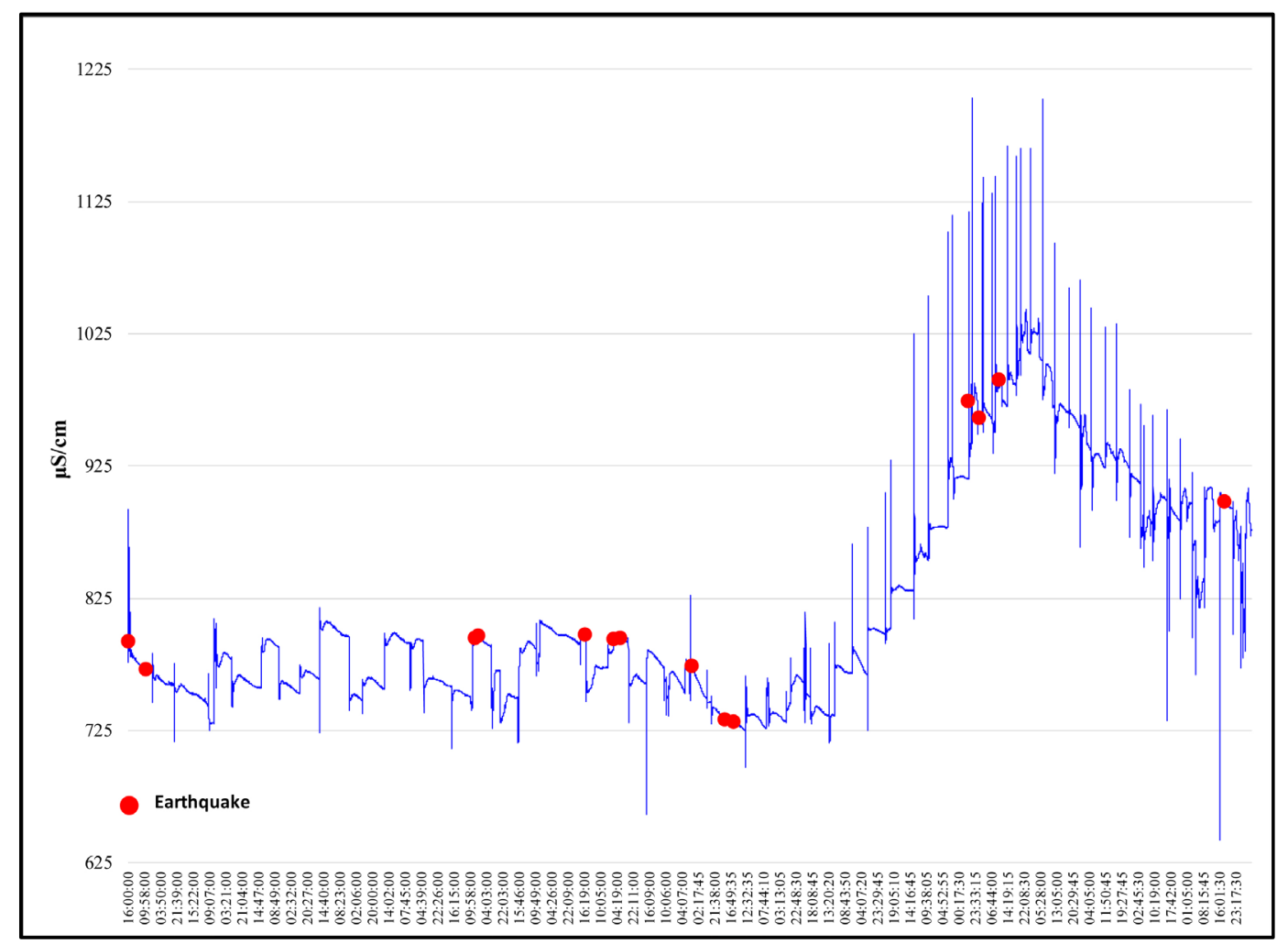

Figure 7. Site CAW01: Possible correlation between the conductivity records and earthquakes in a horizontal range of $250-300 \mathrm{~km}$ around the sensor $(\mu \mathrm{S} / \mathrm{cm})$ within the continental environment. 


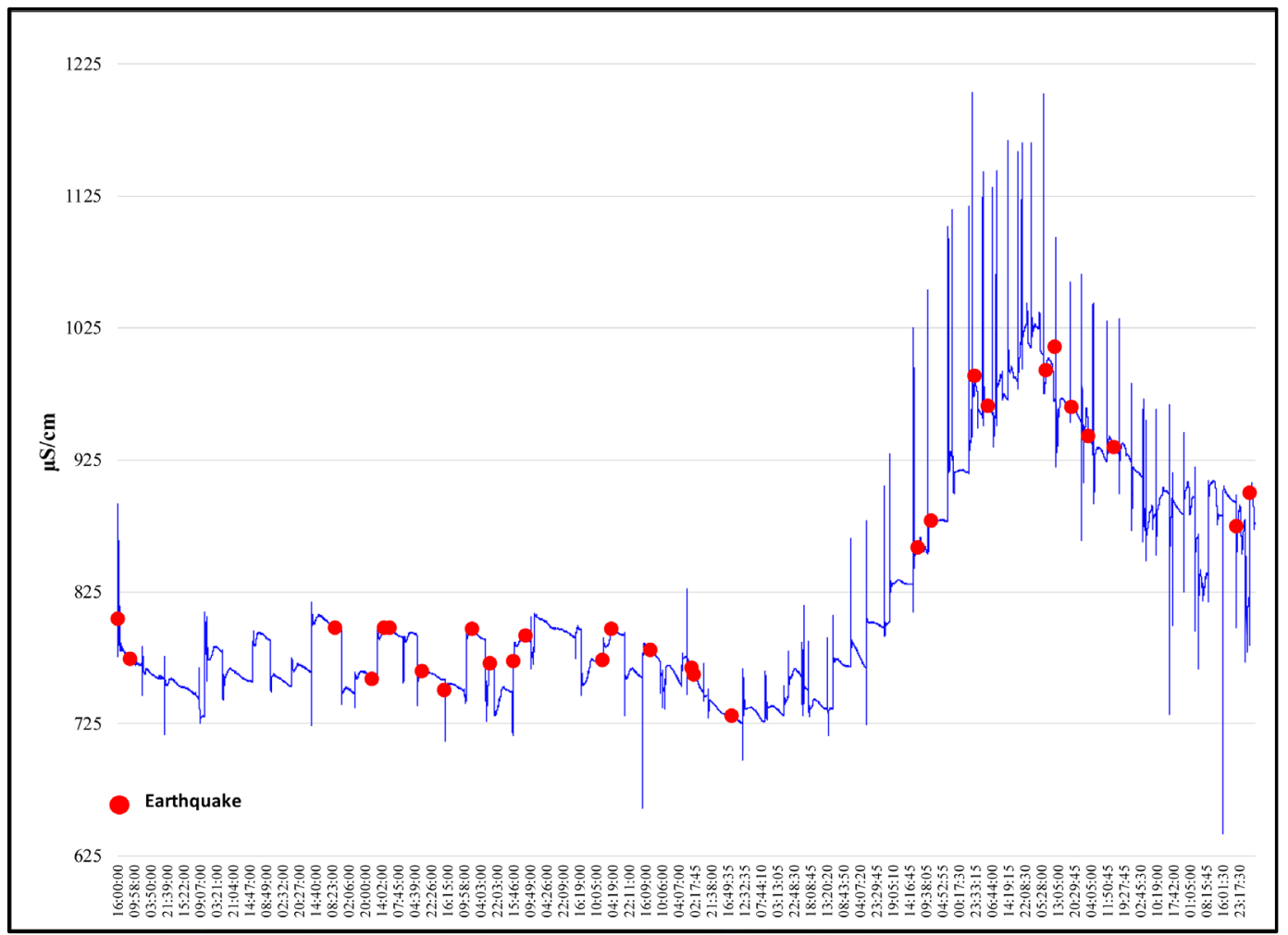

Figure 8. Site CAW01: Possible correlation between the conductivity records and earthquakes in a horizontal range of $300-350 \mathrm{~km}$ around the sensor $(\mu \mathrm{S} / \mathrm{cm})$ within the continental environment.

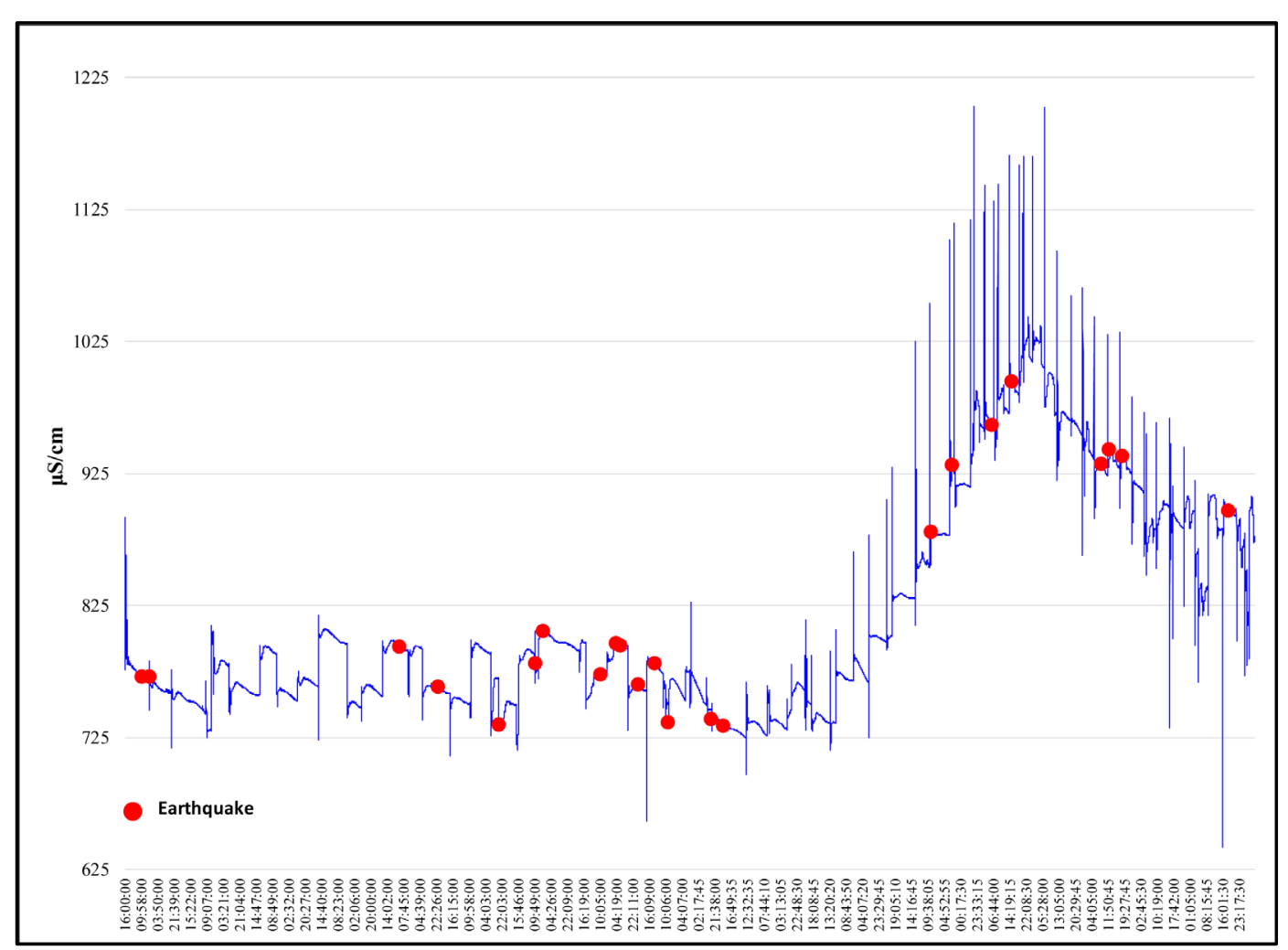

Figure 9. Site CAW01: Possible correlation between the conductivity records and earthquakes in a horizontal range of $350-400 \mathrm{~km}$ around the sensor $(\mu \mathrm{S} / \mathrm{cm})$ within the continental environment. 


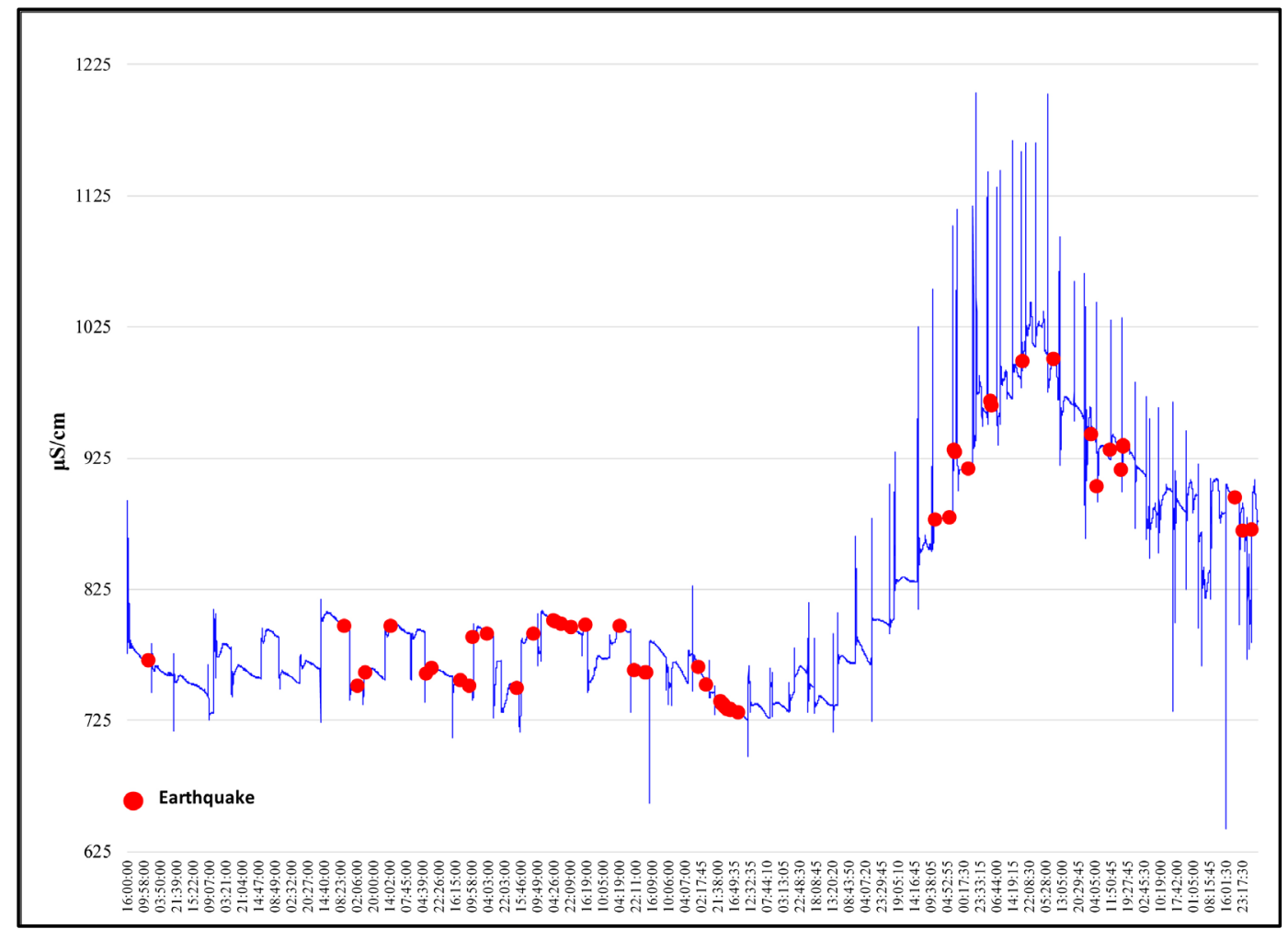

Figure 10. Site CAW01: Possible correlation between the conductivity records and earthquakes in a horizontal range of $0-50 \mathrm{~km}$ around the sensor $(\mu \mathrm{S} / \mathrm{cm})$ within the marine environment.

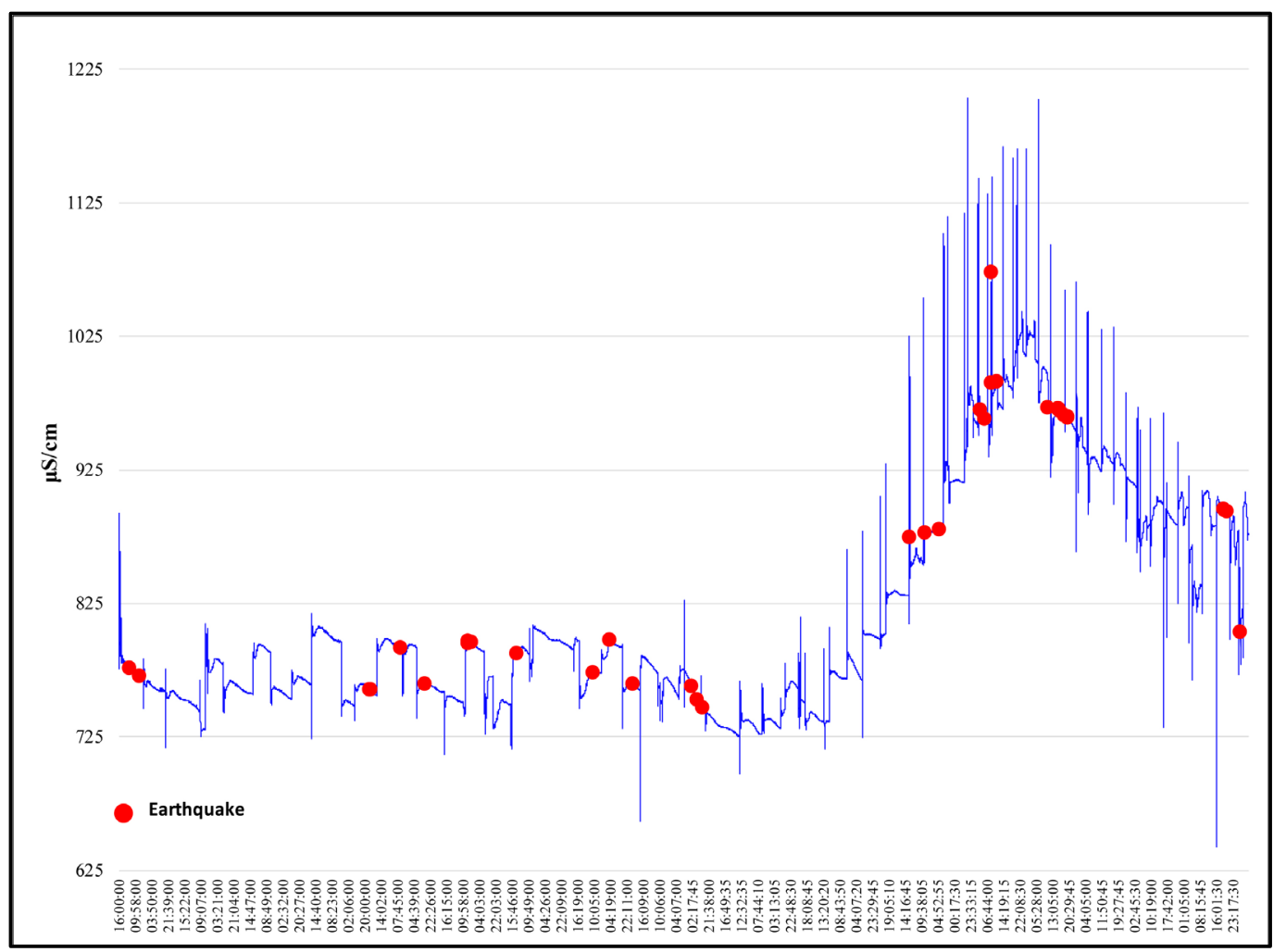

Figure 11. Site CAW01: Possible correlation between the conductivity records and earthquakes in a horizontal range of $50-100 \mathrm{~km}$ around the sensor $(\mu \mathrm{S} / \mathrm{cm})$ within the marine environment. 


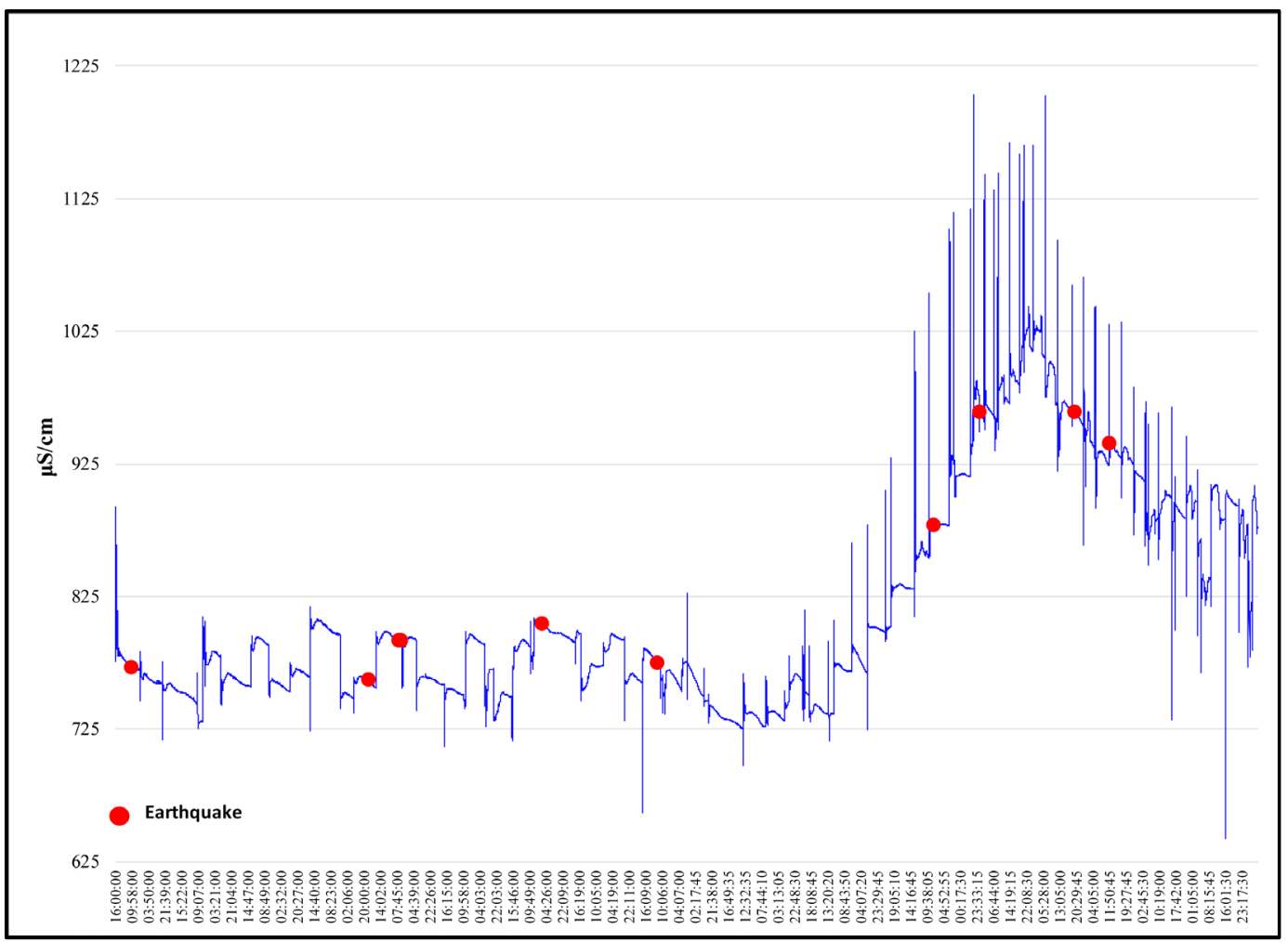

Figure 12. Site CAW01: Possible correlation between the conductivity records and earthquakes in a horizontal range of $100-150 \mathrm{~km}$ around the sensor $(\mu \mathrm{S} / \mathrm{cm})$ within the marine environment.

1225

1025

总 92

725

Earthquake

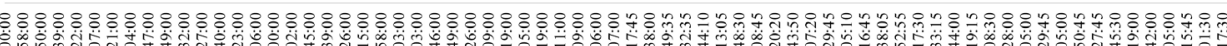

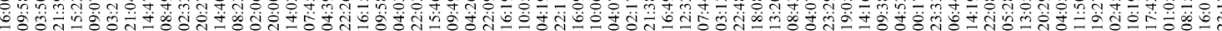

Figure 13. Site CAW01: Possible correlation between the conductivity records and earthquakes in a horizontal range of $150-200 \mathrm{~km}$ around the sensor $(\mu \mathrm{S} / \mathrm{cm})$ within the marine environment. 


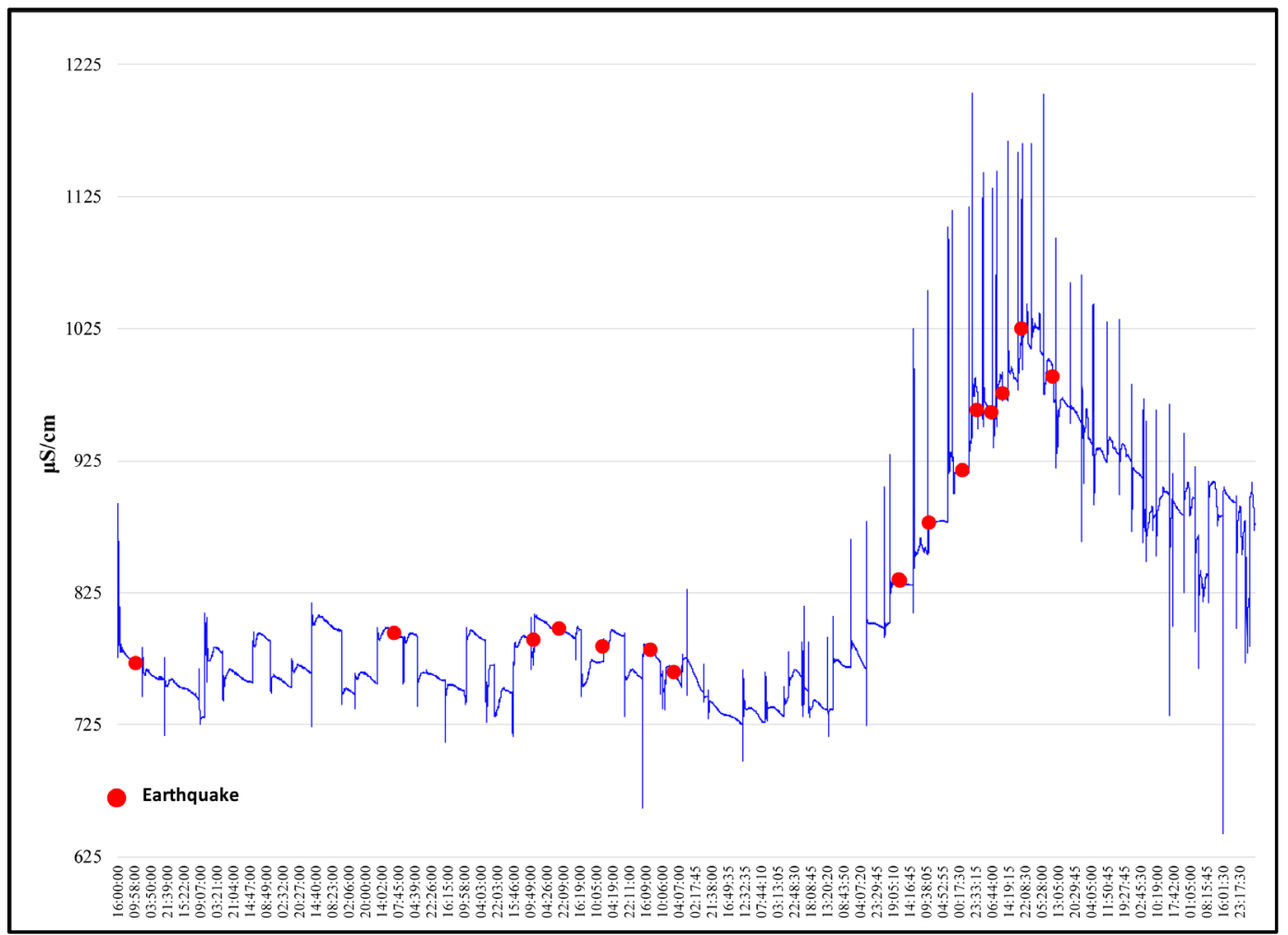

Figure 14. Site CAW01: Possible correlation between the conductivity records and earthquakes in a horizontal range of $200-250 \mathrm{~km}$ around the sensor $(\mu \mathrm{S} / \mathrm{cm})$ within the marine environment.

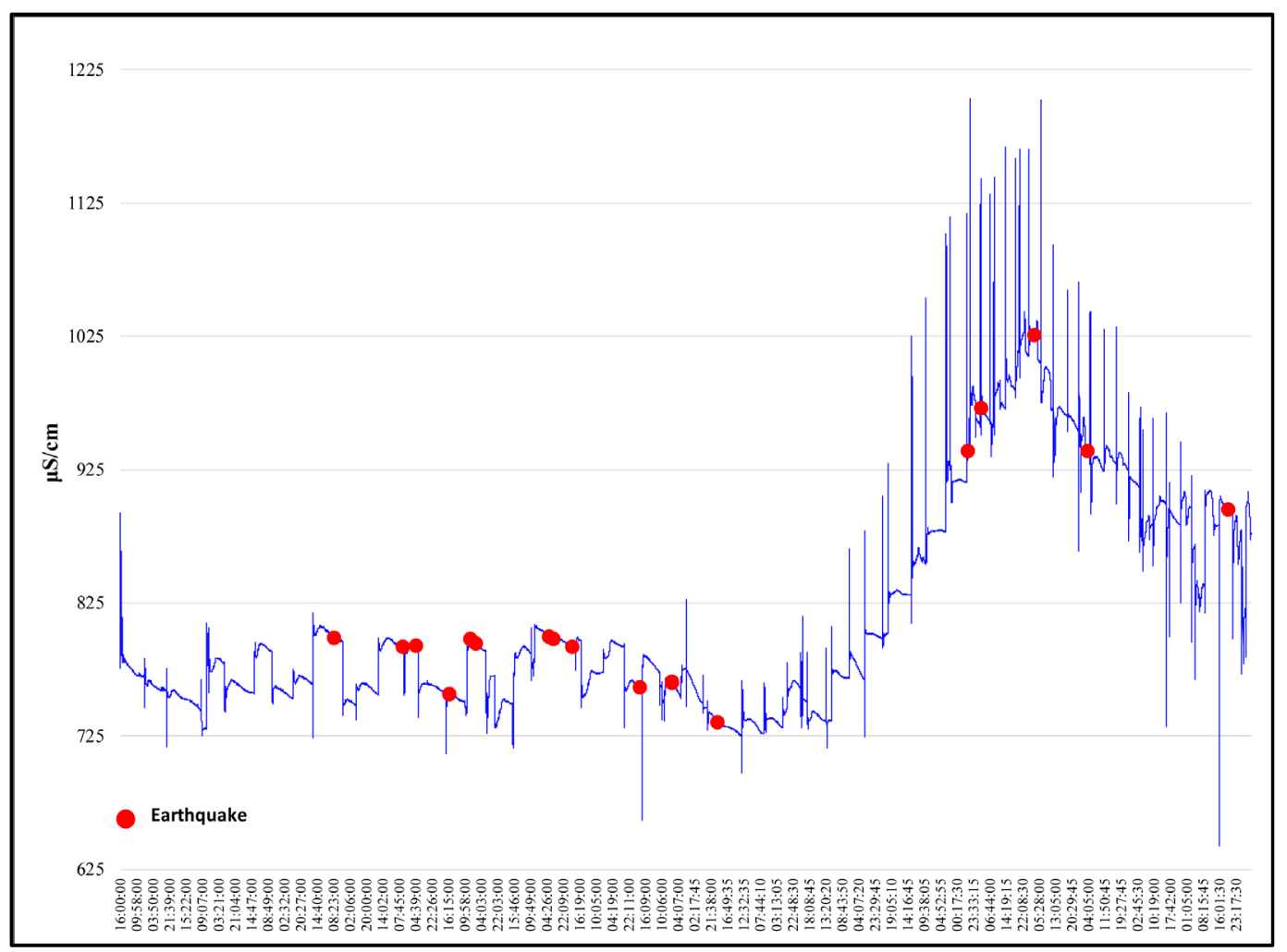

Figure 15. Site CAW01: Possible correlation between the conductivity records and earthquakes in a horizontal range of $250-300 \mathrm{~km}$ around the sensor $(\mu \mathrm{S} / \mathrm{cm})$ within the marine environment. 


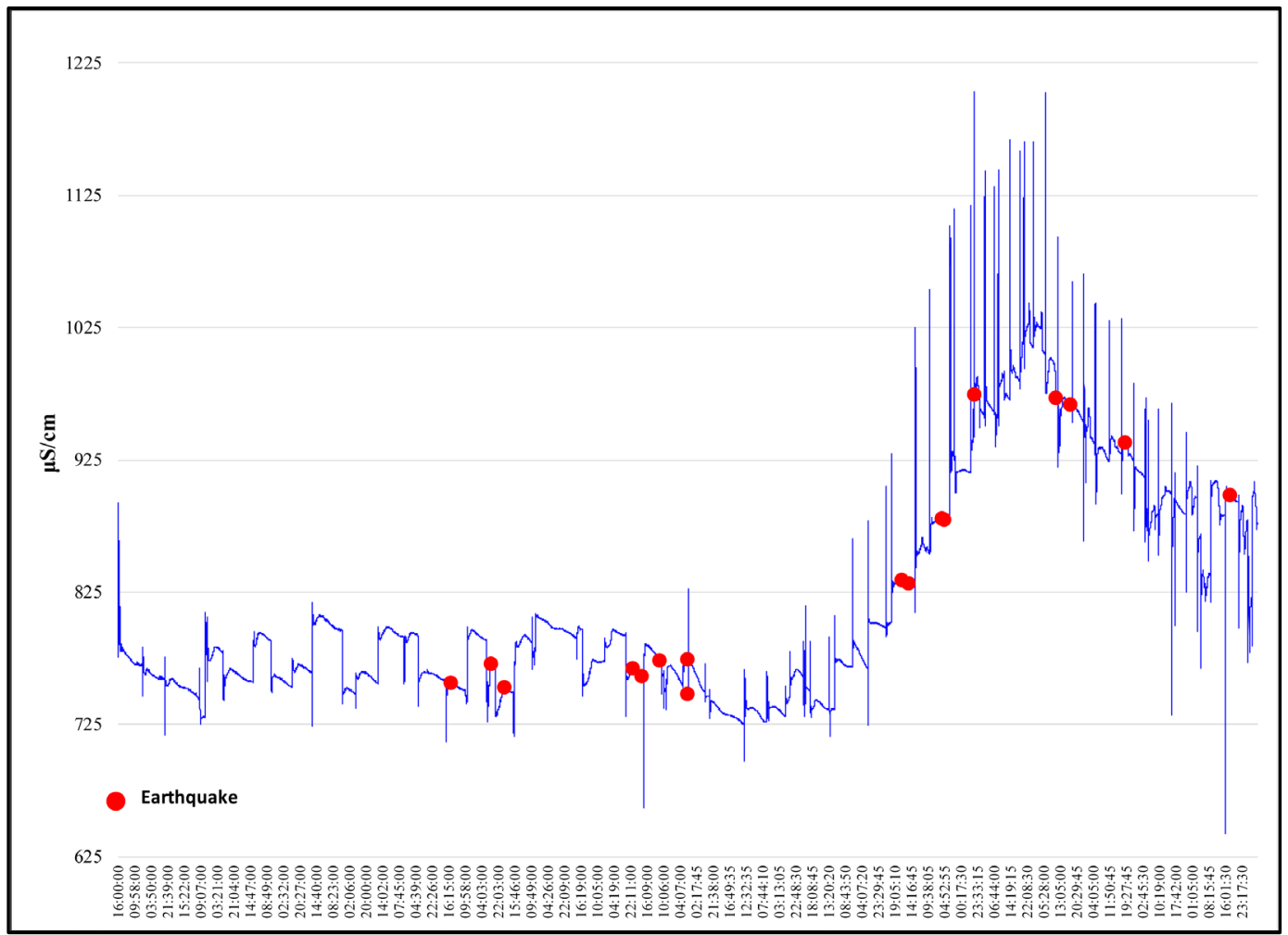

Figure 16. Site CAW01: Possible correlation between the conductivity records and earthquakes in a horizontal range of $300-350 \mathrm{~km}$ around the sensor $(\mu \mathrm{S} / \mathrm{cm})$ within the marine environment.

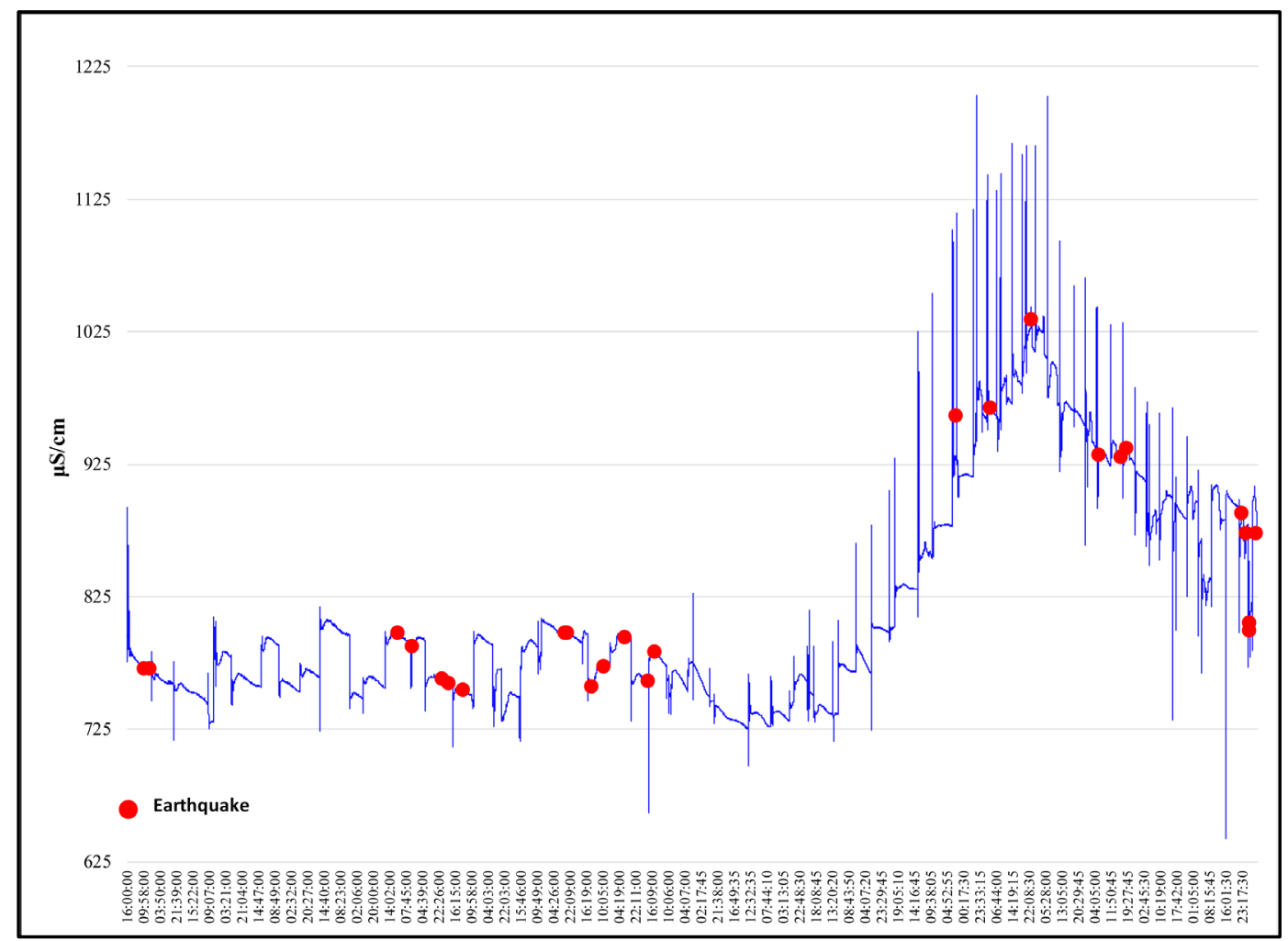

Figure 17. Site CAW01: Possible correlation between the conductivity records and earthquakes in a horizontal range of $350-400 \mathrm{~km}$ around the sensor $(\mu \mathrm{S} / \mathrm{cm})$ within the marine environment. 


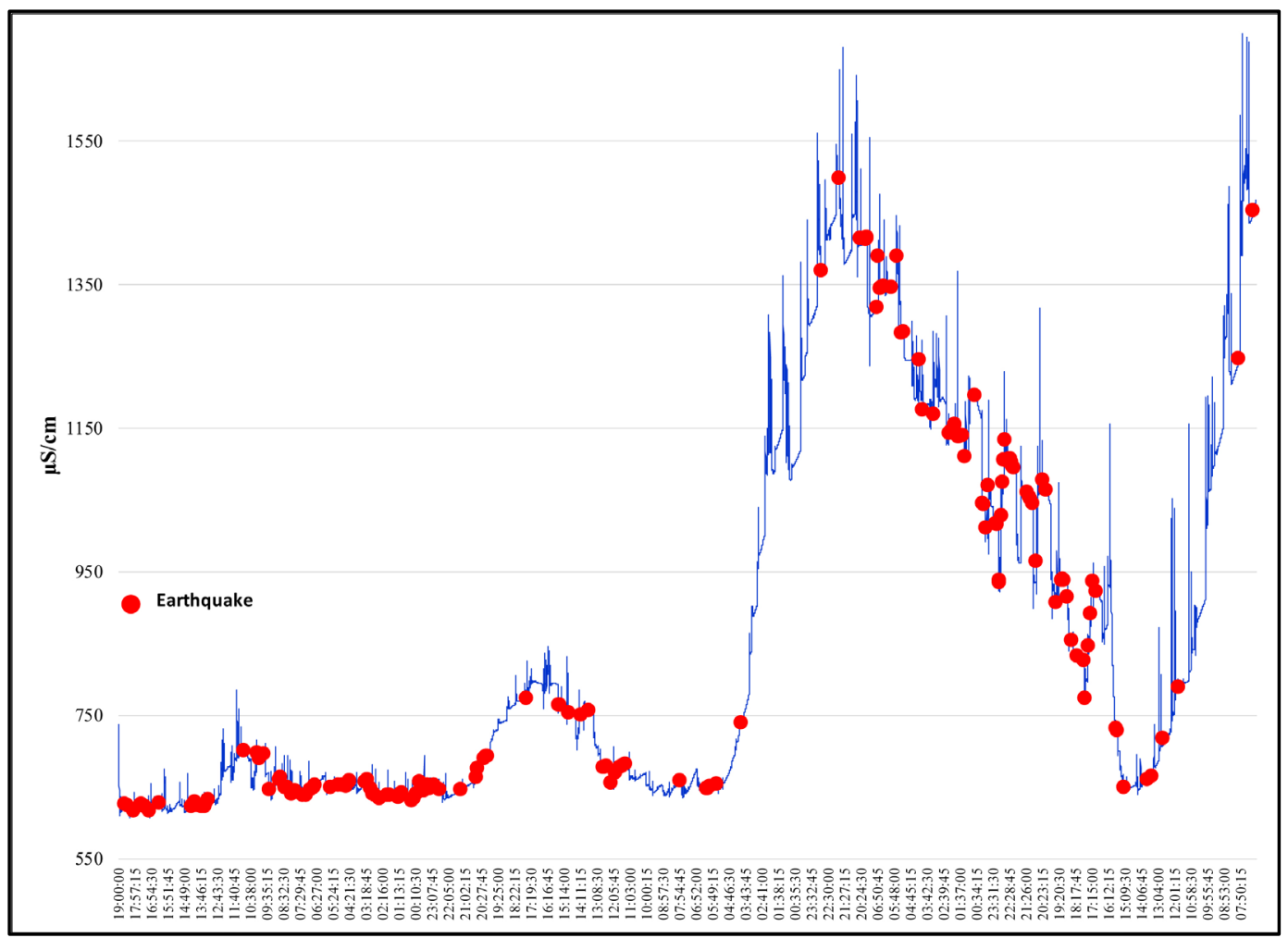

Figure 18. Site CAW02: Possible correlation between the conductivity records and earthquakes in a horizontal range of $0-50 \mathrm{~km}$ around the sensor $(\mu \mathrm{S} / \mathrm{cm})$ within the continental environment.

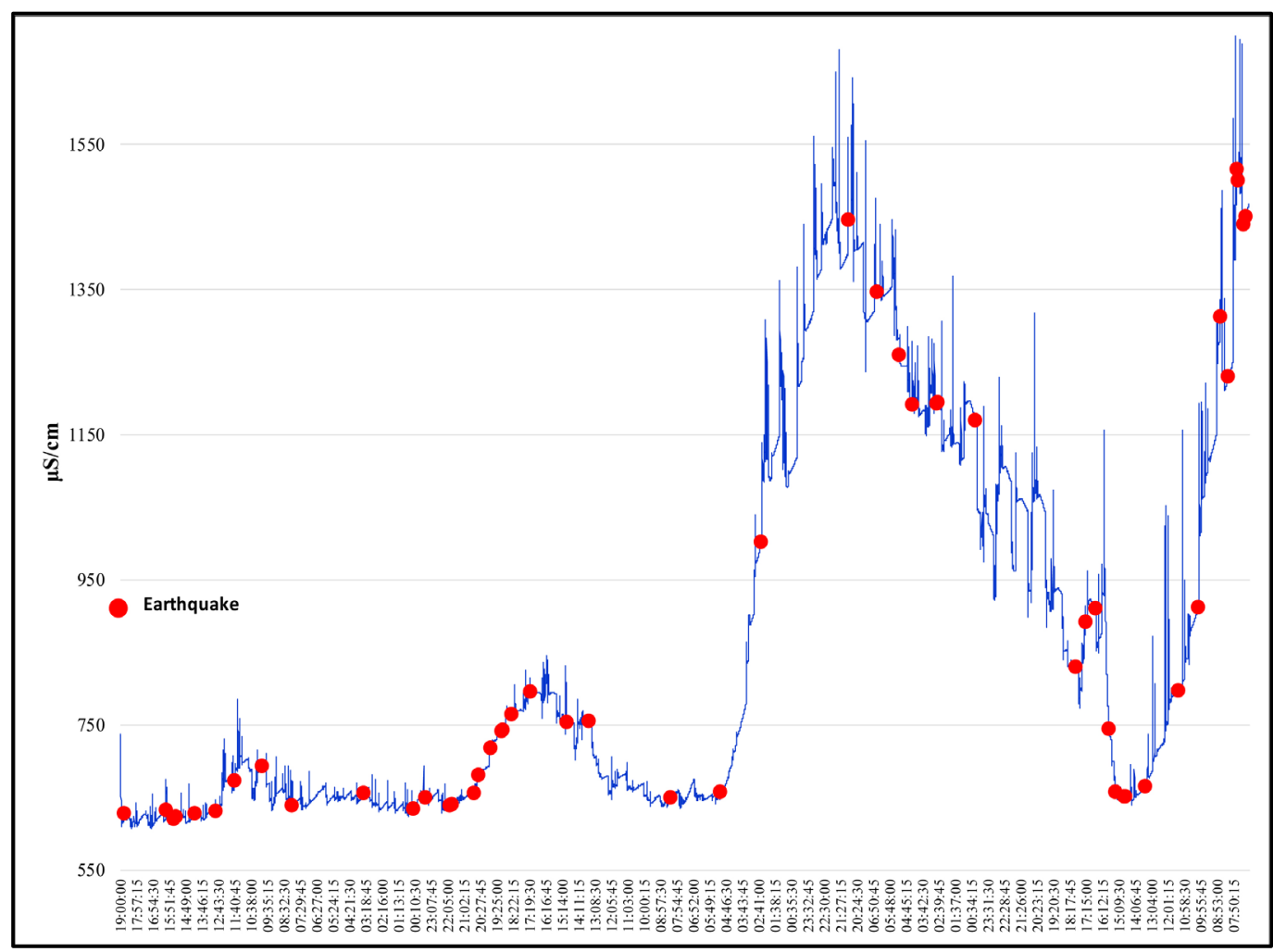

Figure 19. Site CAW02: Possible correlation between the conductivity records and earthquakes in a horizontal range of $50-100 \mathrm{~km}$ around the sensor $(\mu \mathrm{S} / \mathrm{cm})$ within the continental environment. 


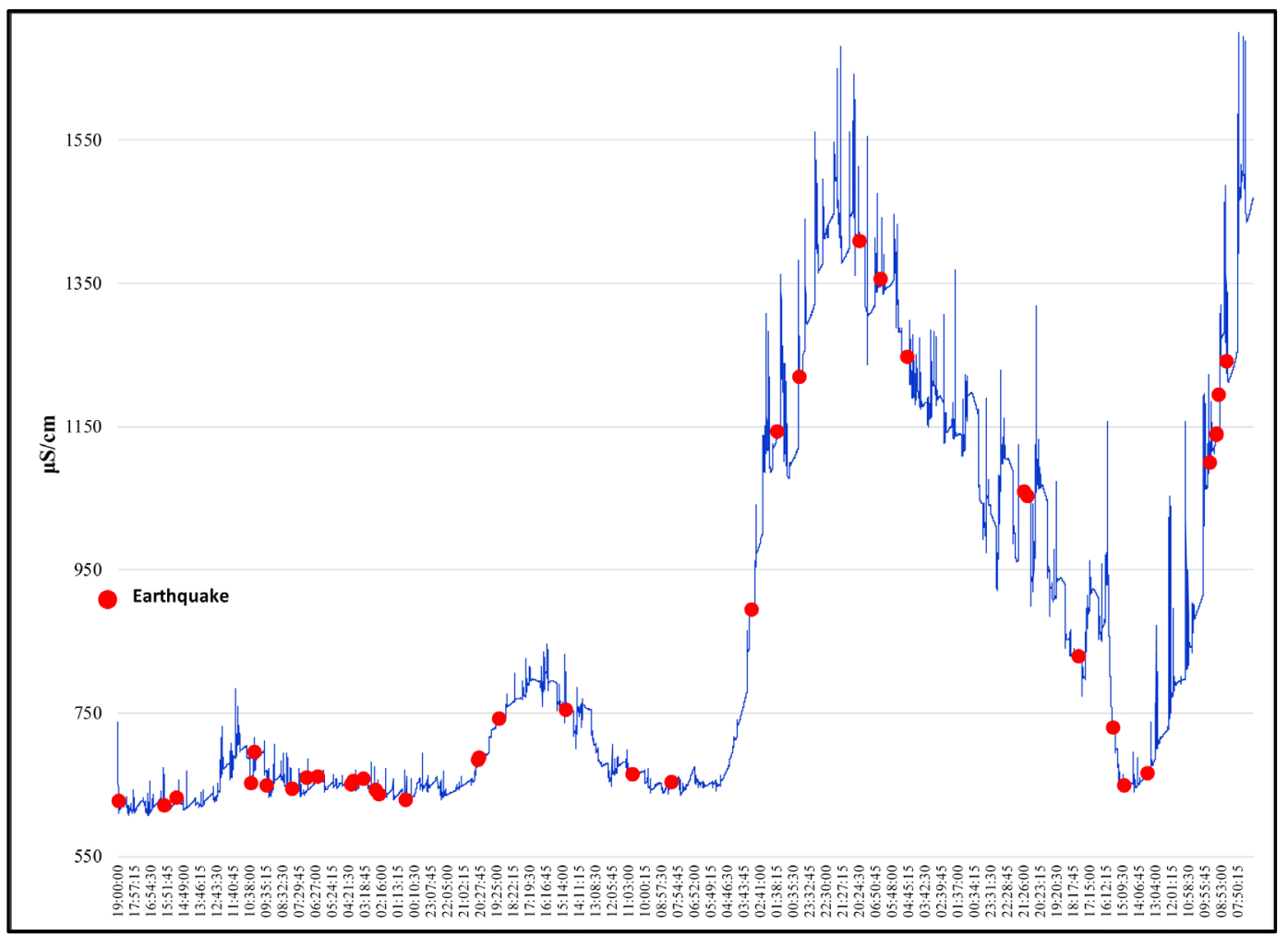

Figure 20. Site CAW02: Possible correlation between the conductivity records and earthquakes in a horizontal range of $100-150 \mathrm{~km}$ around the sensor $(\mu \mathrm{S} / \mathrm{cm})$ within the continental environment.

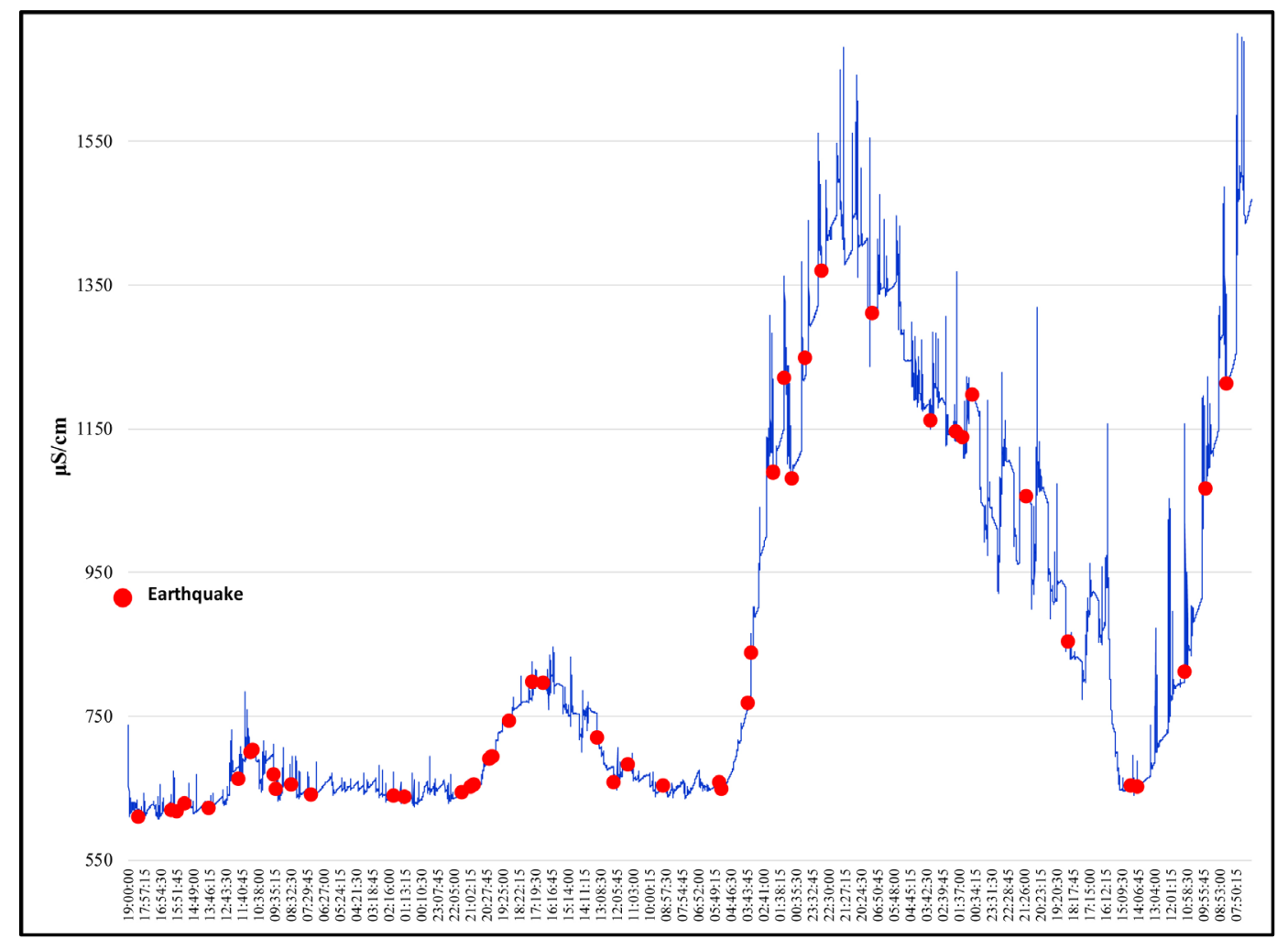

Figure 21. Site CAW02: Possible correlation between the conductivity records and earthquakes in a horizontal range of $150-200 \mathrm{~km}$ around the sensor $(\mu \mathrm{S} / \mathrm{cm})$ within the continental environment. 


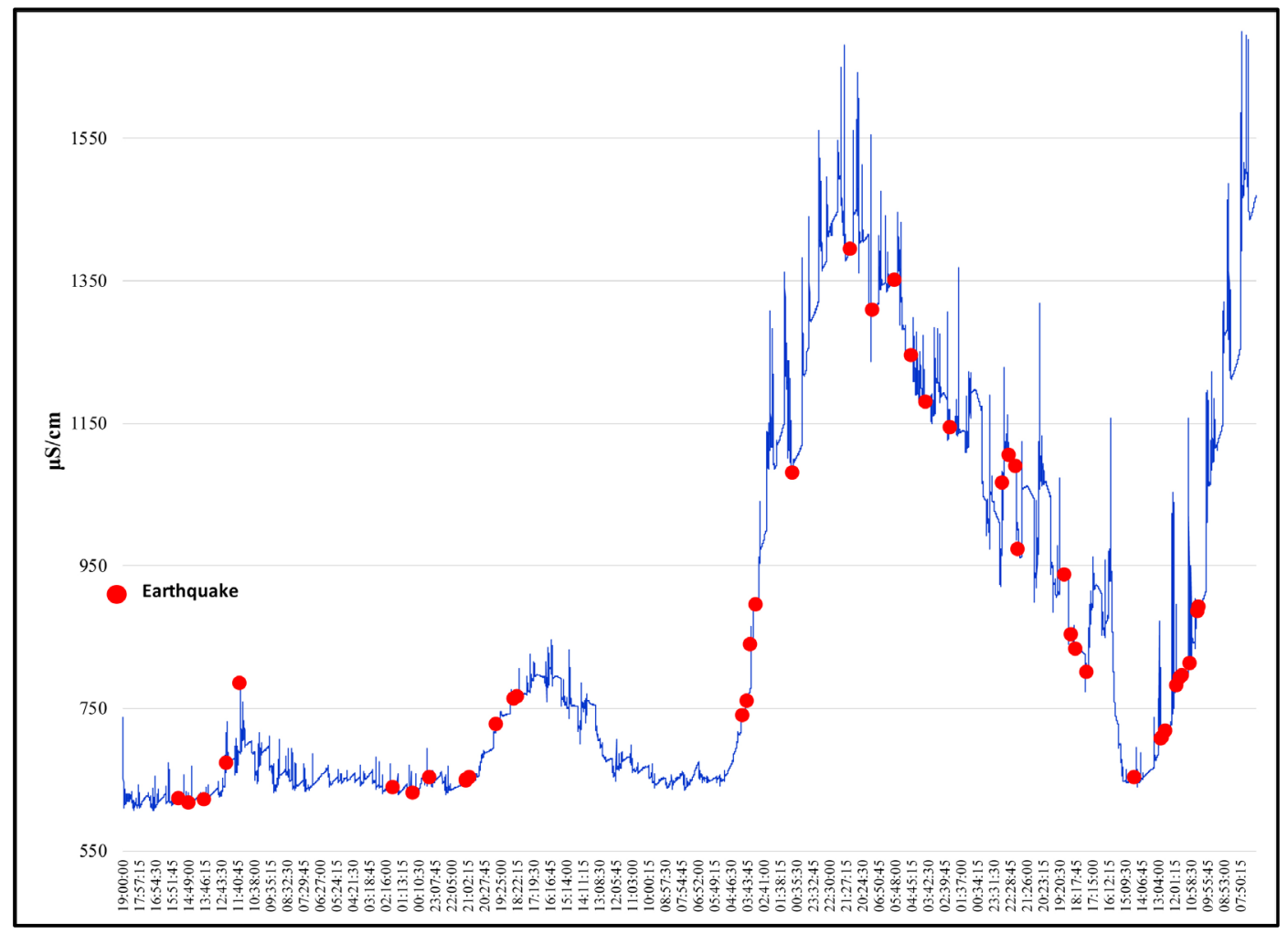

Figure 22. Site CAW02: Possible correlation between the conductivity records and earthquakes in a horizontal range of $200-250 \mathrm{~km}$ around the sensor $(\mu \mathrm{S} / \mathrm{cm})$ within the continental environment.

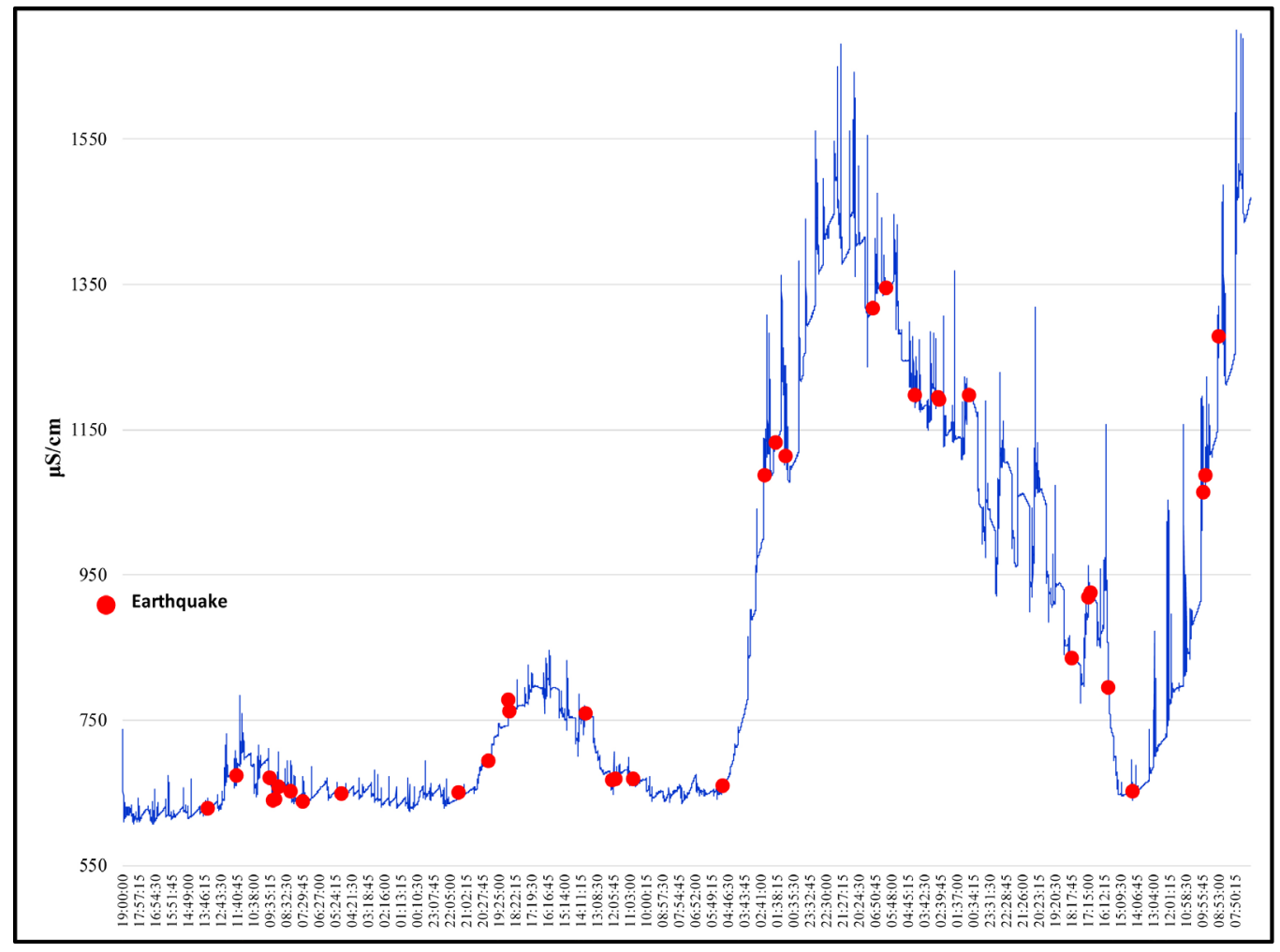

Figure 23. Site CAW02: Possible correlation between the conductivity records and earthquakes in a horizontal range of $250-300 \mathrm{~km}$ around the sensor $(\mu \mathrm{S} / \mathrm{cm})$ within the continental environment. 


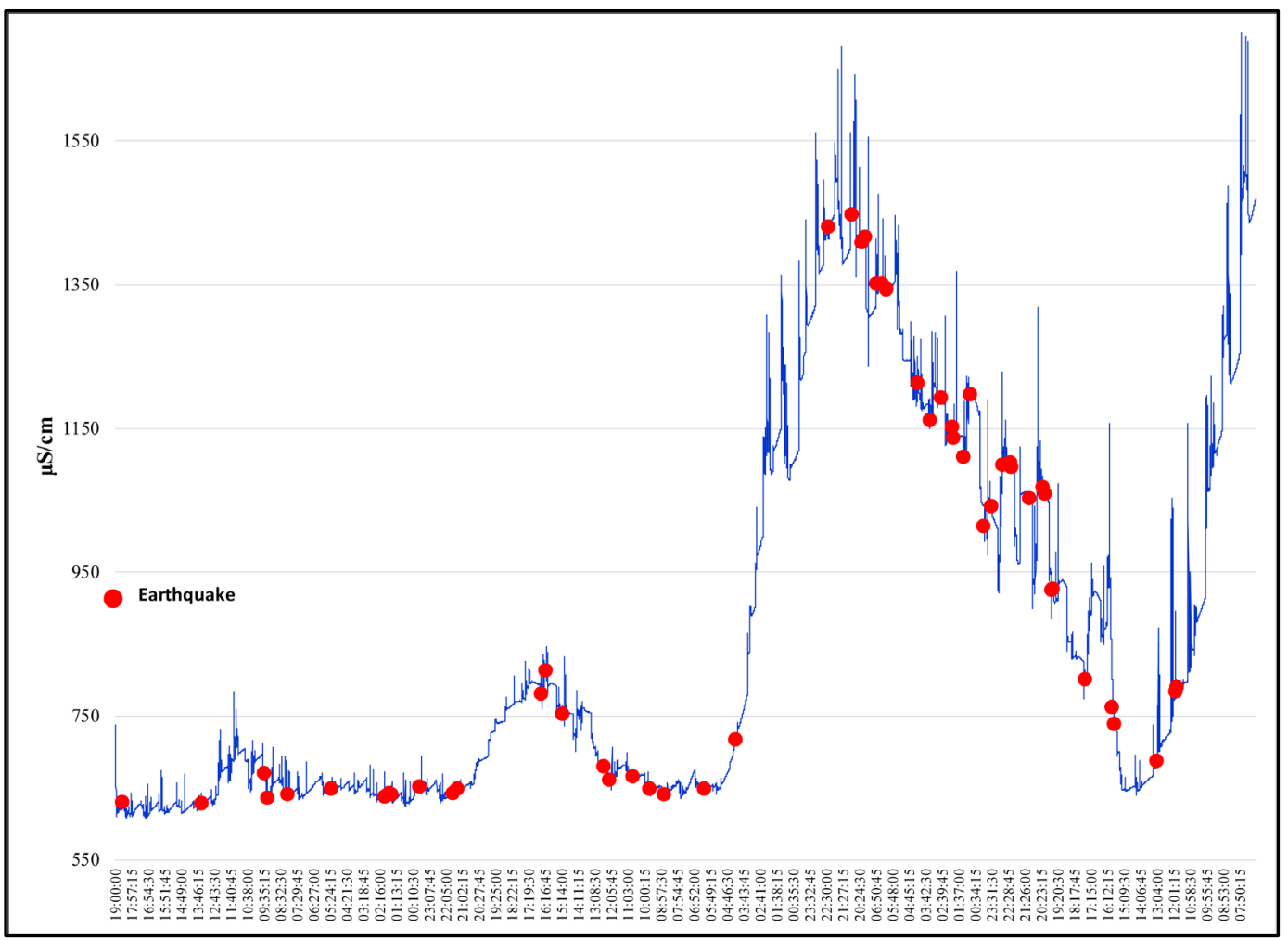

Figure 24. Site CAW02: Possible correlation between the conductivity records and earthquakes in a horizontal range of $300-350 \mathrm{~km}$ around the sensor $(\mu \mathrm{S} / \mathrm{cm})$ within the continental environment.

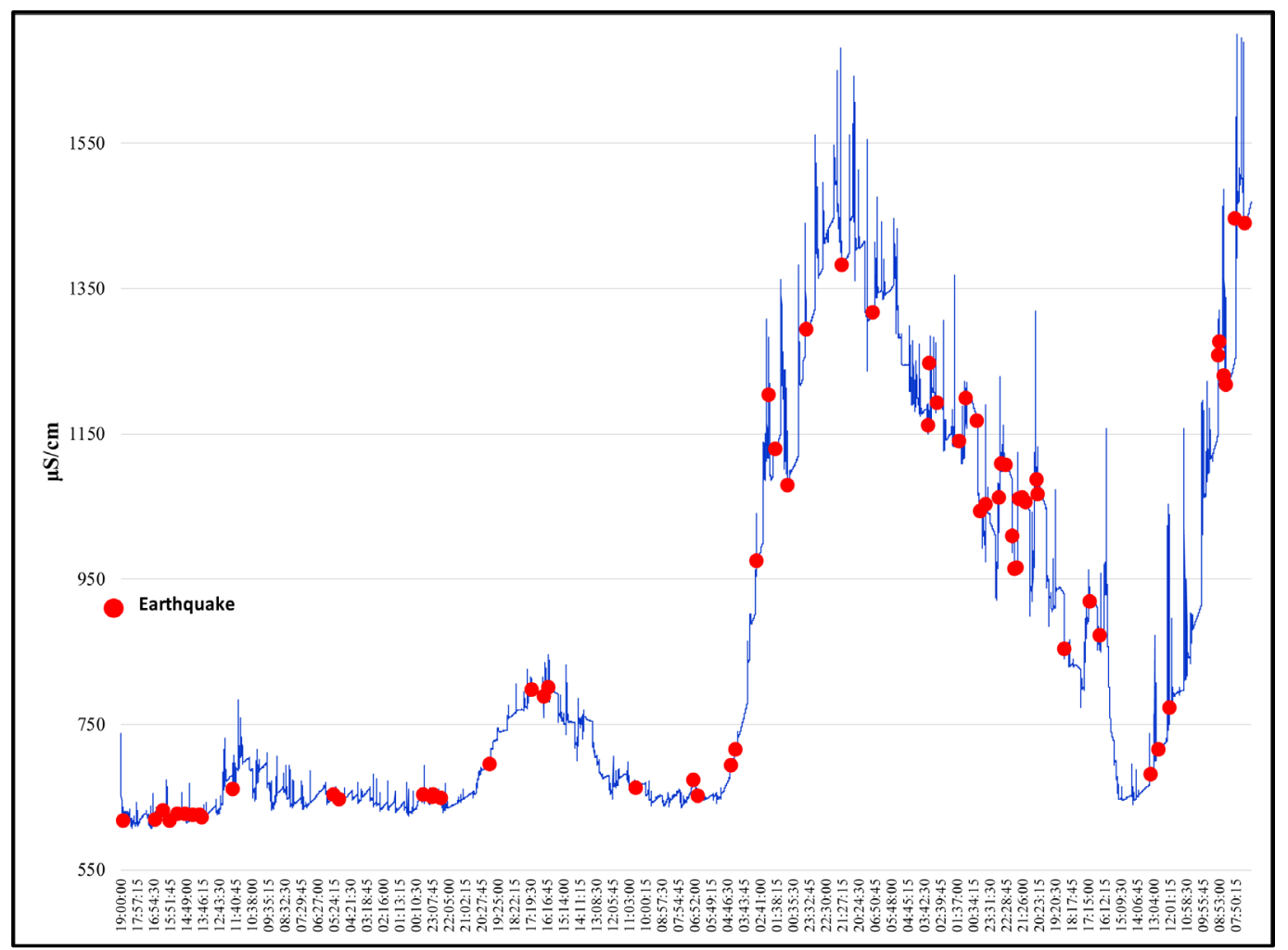

Figure 25. Site CAW02: Possible correlation between the conductivity records and earthquakes in a horizontal range of $350-400 \mathrm{~km}$ around the sensor $(\mu \mathrm{S} / \mathrm{cm})$ within the continental environment. 


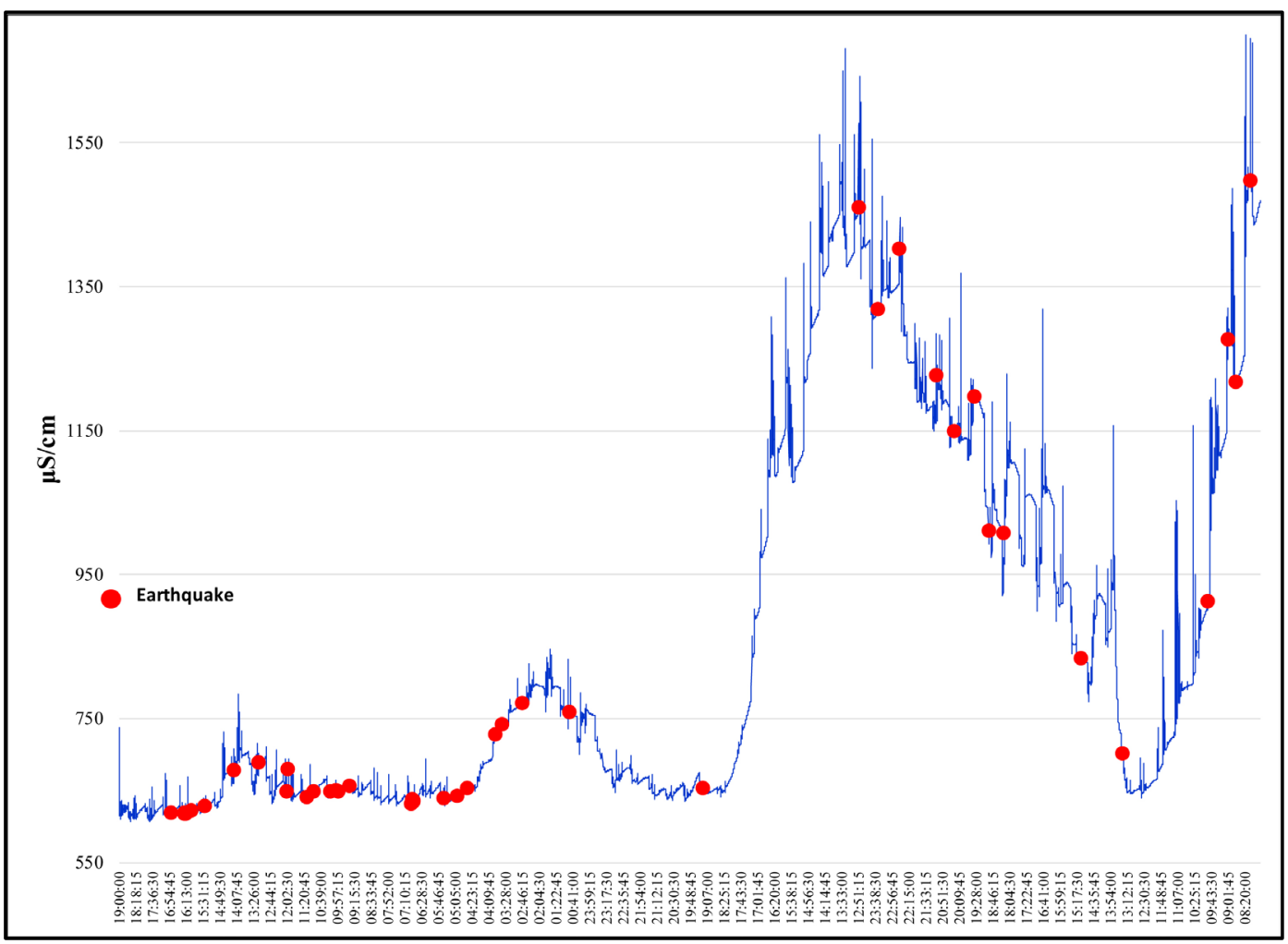

Figure 26. Site CAW02: Possible correlation between the conductivity records and earthquakes in a horizontal range of $0-50 \mathrm{~km}$ around the sensor $(\mu \mathrm{S} / \mathrm{cm})$ within the marine environment.

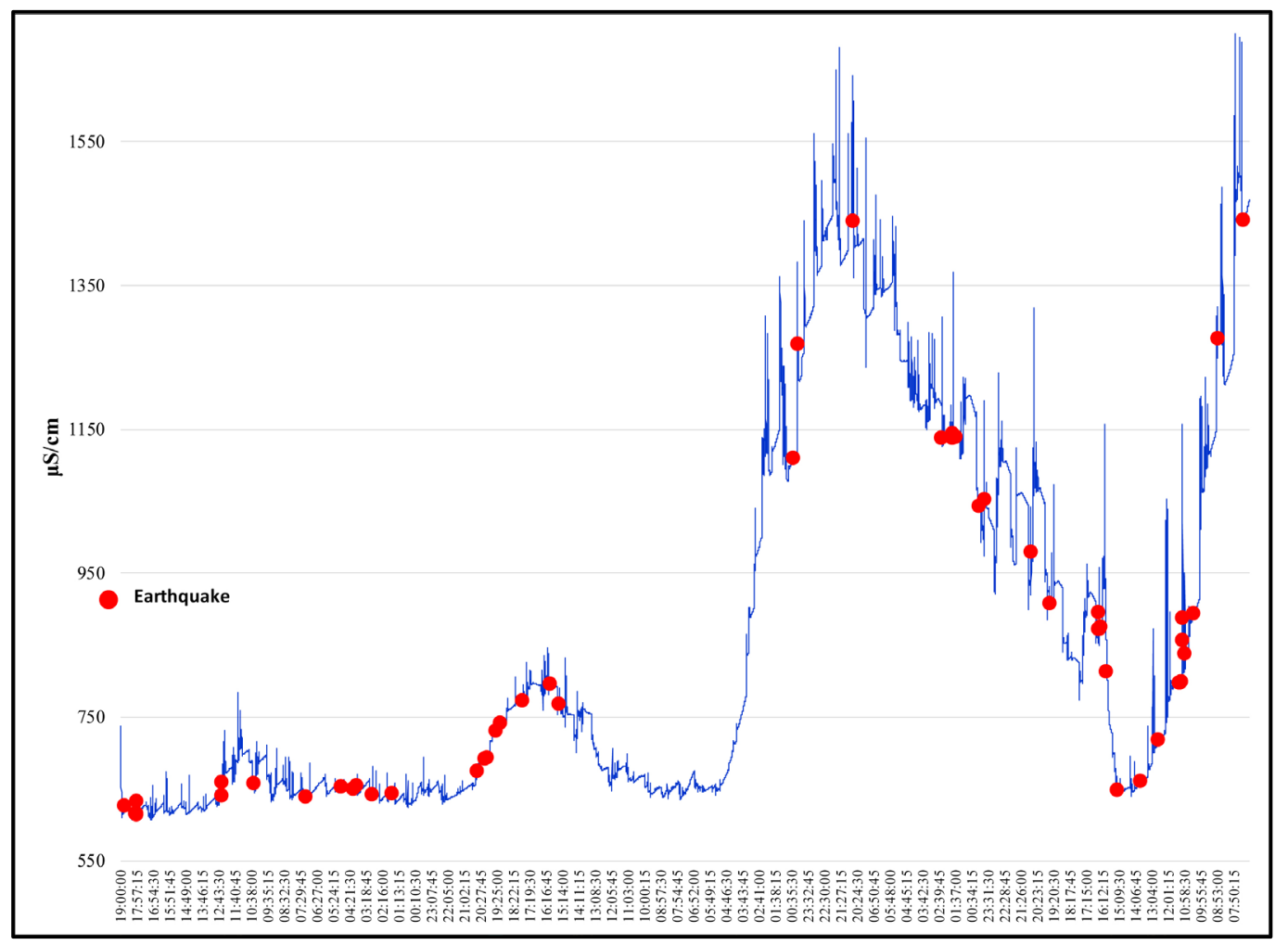

Figure 27. Site CAW02: Possible correlation between the conductivity records and earthquakes in a horizontal range of $50-100 \mathrm{~km}$ around the sensor $(\mu \mathrm{S} / \mathrm{cm})$ within the marine environment. 


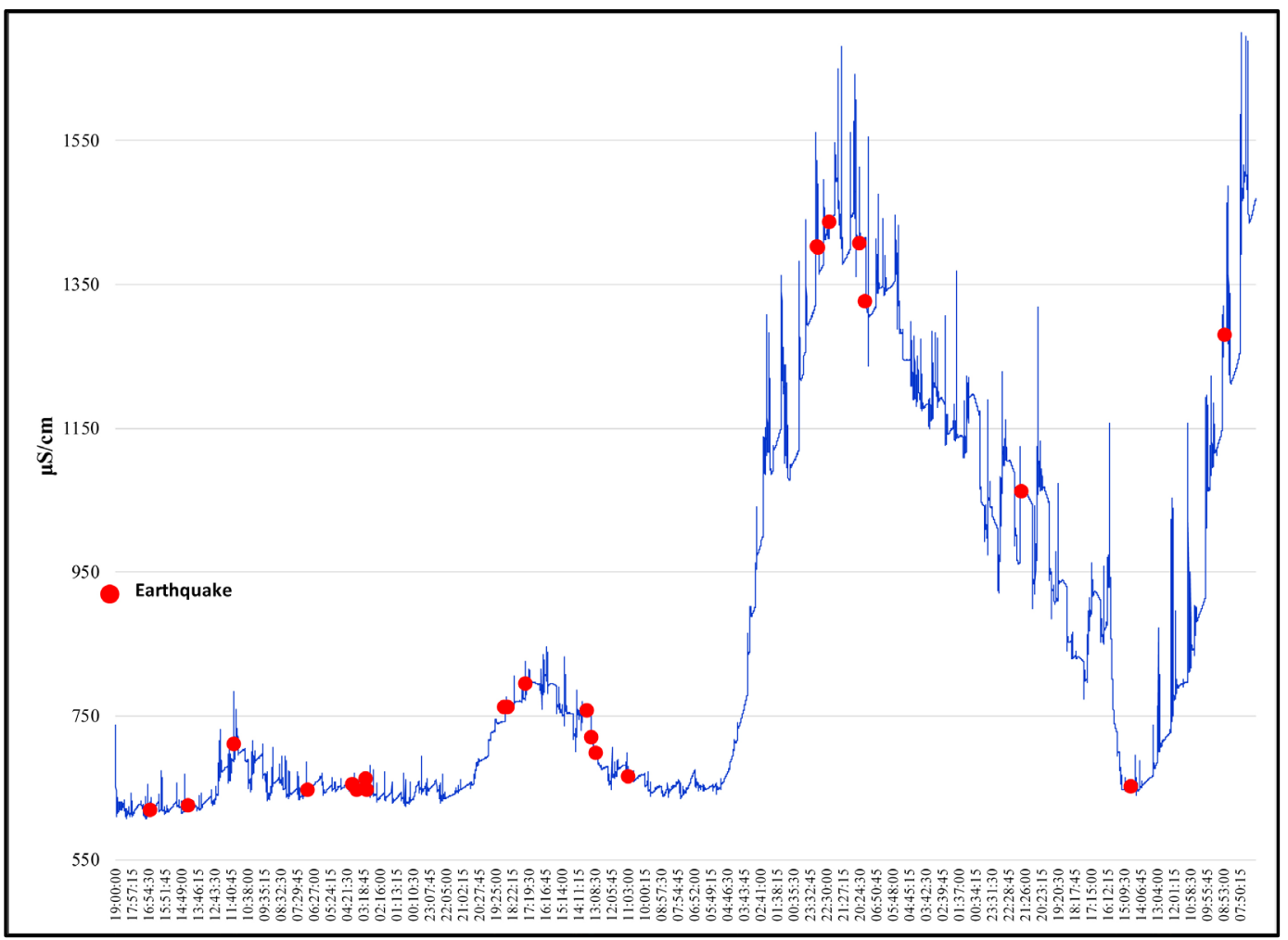

Figure 28. Site CAW02: Possible correlation between the conductivity records and earthquakes in a horizontal range of $100-150 \mathrm{~km}$ around the sensor $(\mu \mathrm{S} / \mathrm{cm})$ within the marine environment.

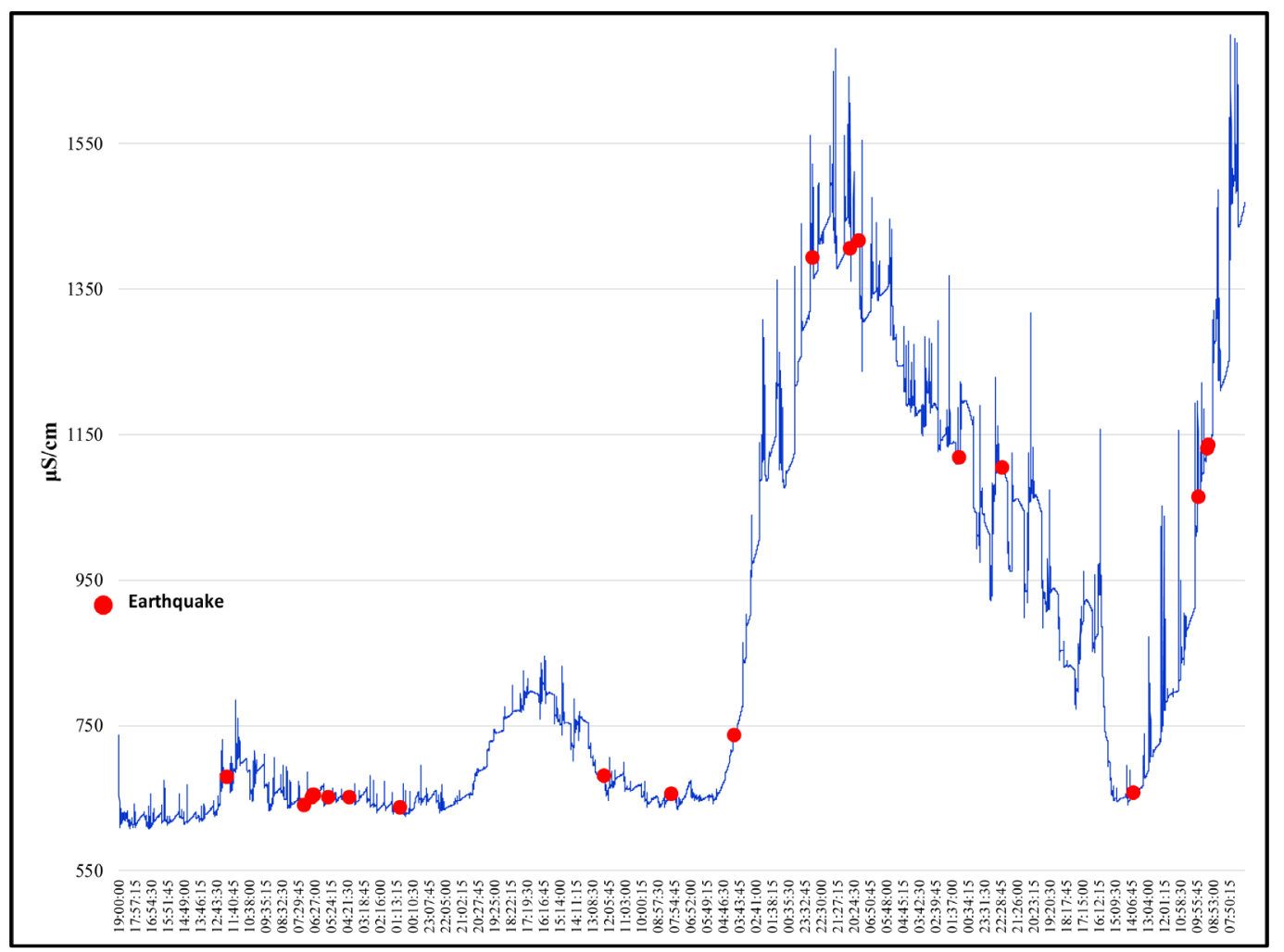

Figure 29. Site CAW02: Possible correlation between the conductivity records and earthquakes in a horizontal range of $150-200 \mathrm{~km}$ around the sensor $(\mu \mathrm{S} / \mathrm{cm})$ within the marine environment. 


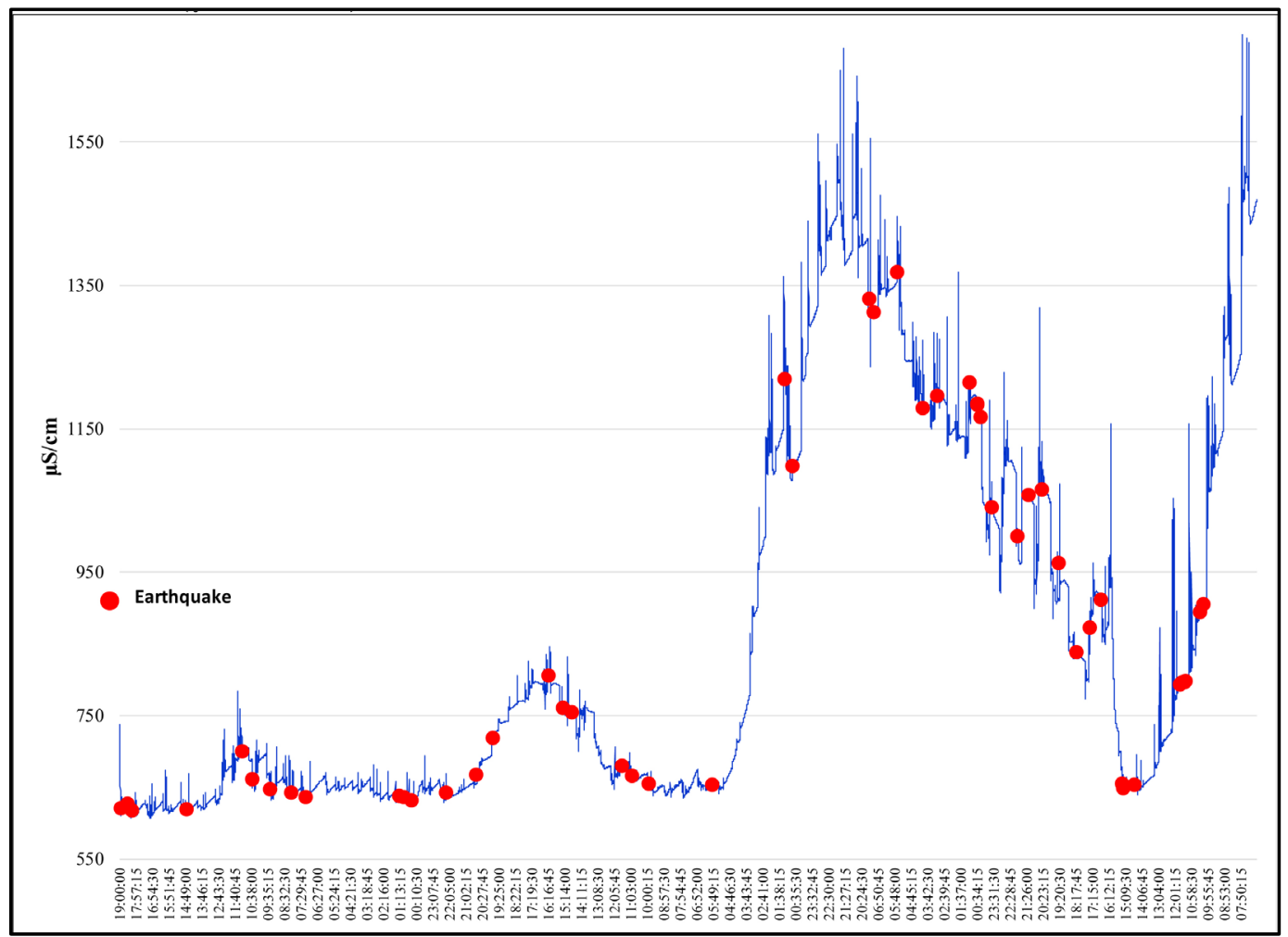

Figure 30. Site CAW02: Possible correlation between the conductivity records and earthquakes in a horizontal range of $200-250 \mathrm{~km}$ around the sensor $(\mu \mathrm{S} / \mathrm{cm})$ within the marine environment.

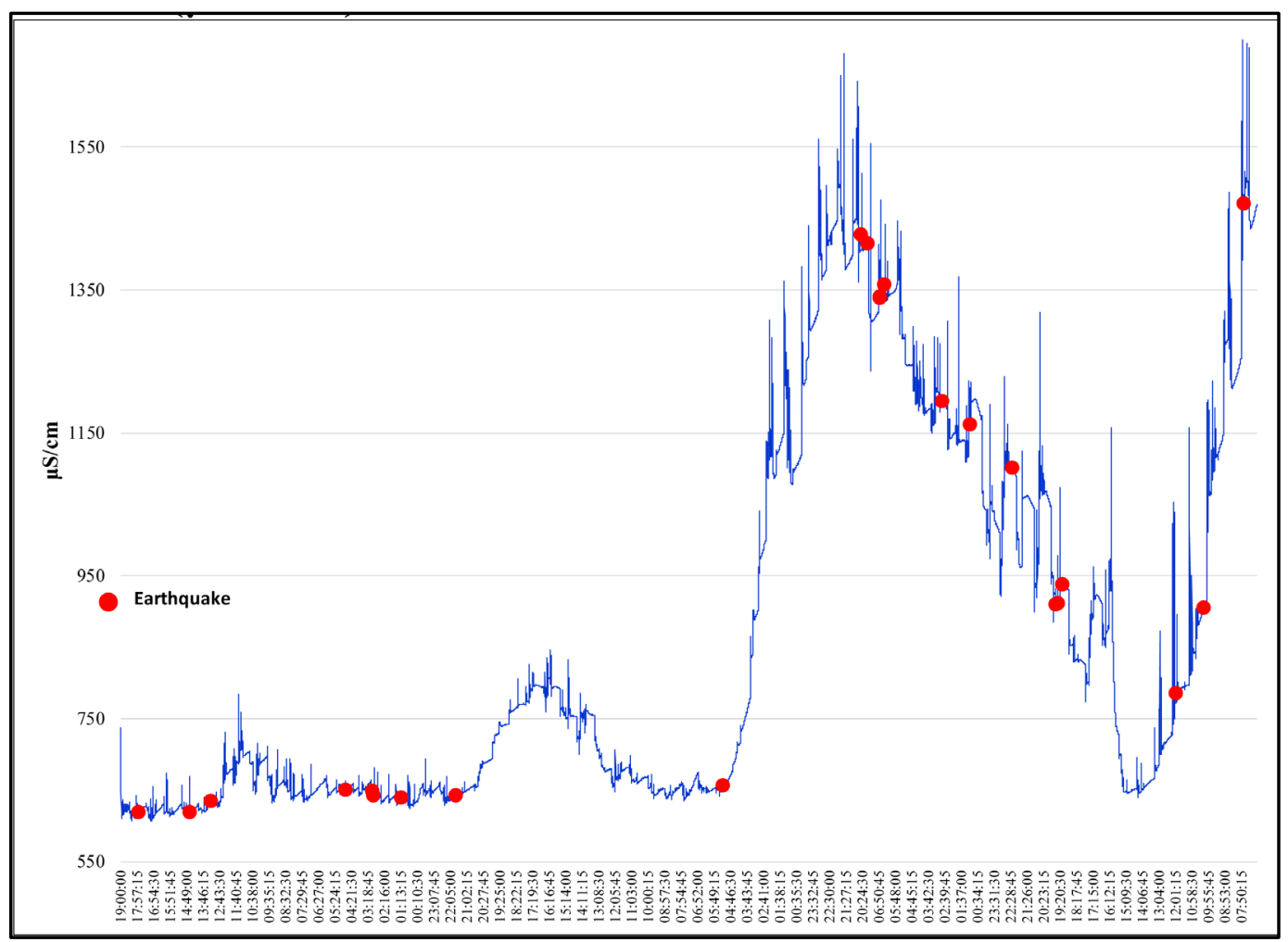

Figure 31. Site CAW02: Possible correlation between the conductivity records and earthquakes in a horizontal range of $250-300 \mathrm{~km}$ around the sensor $(\mu \mathrm{S} / \mathrm{cm})$ within the marine environment. 


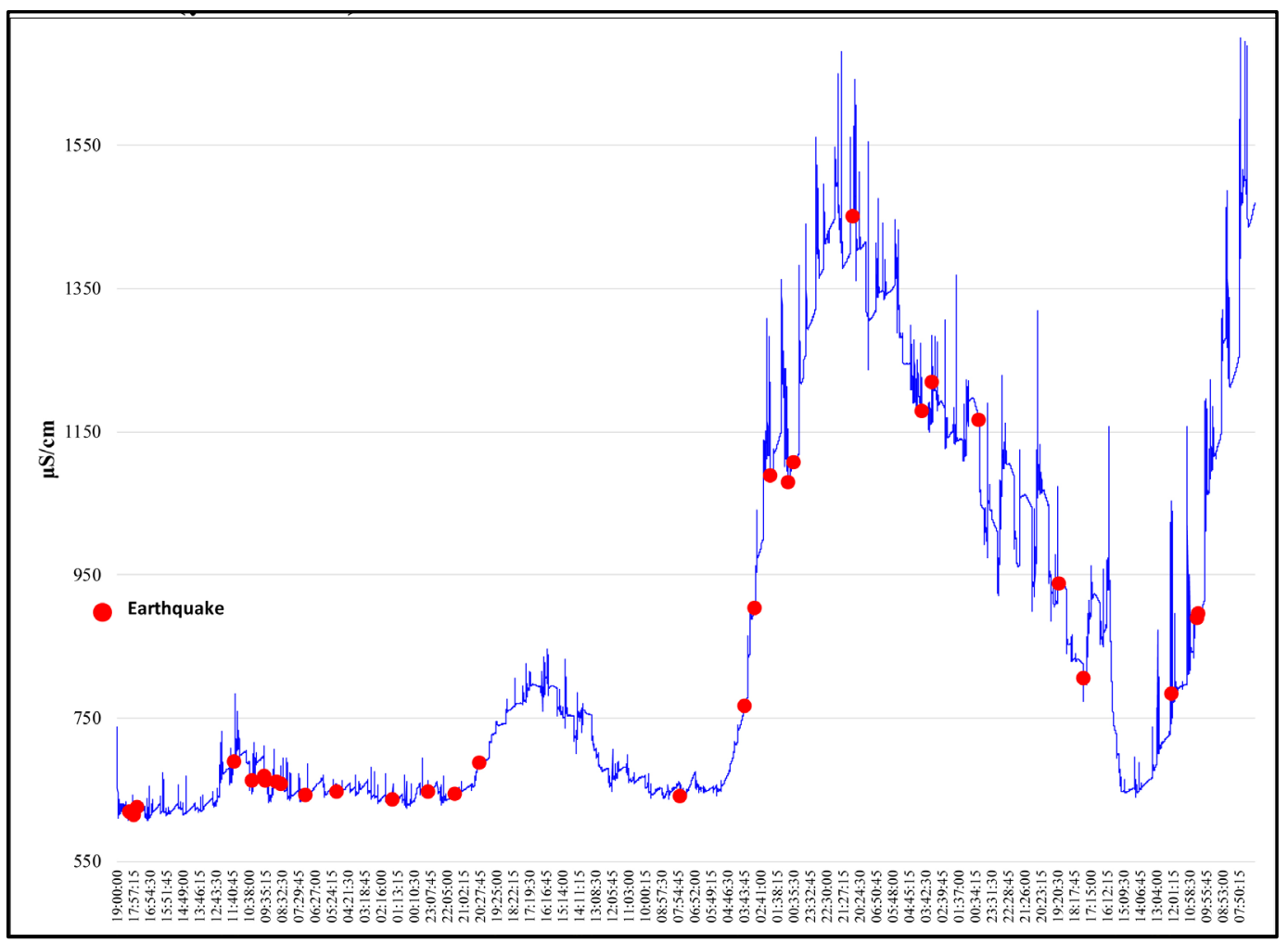

Figure 32. Site CAW02: Possible correlation between the conductivity records and earthquakes in a horizontal range of $300-350 \mathrm{~km}$ around the sensor $(\mu \mathrm{S} / \mathrm{cm})$ within the marine environment.

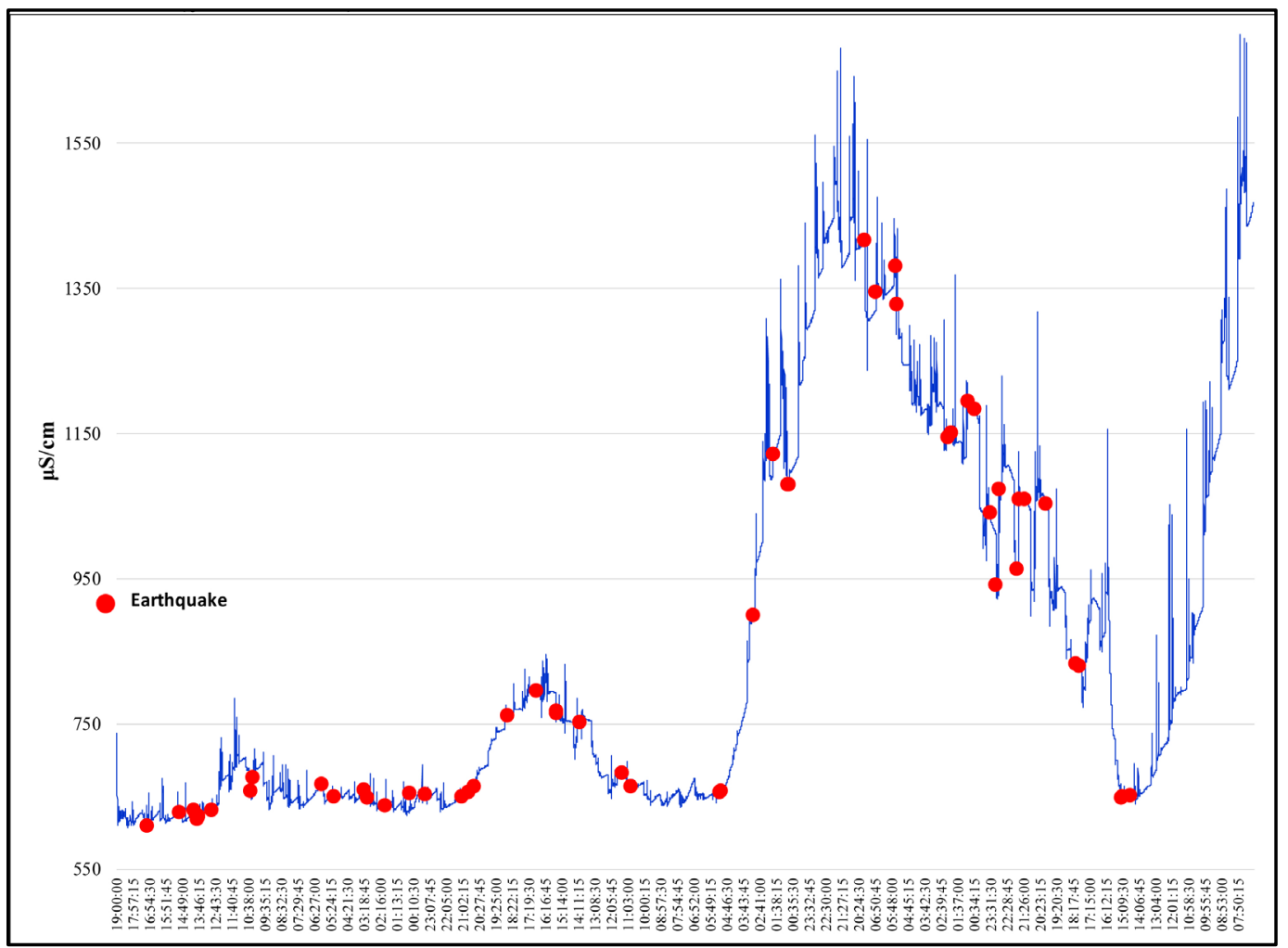

Figure 33. Site CAW02: Possible correlation between the conductivity records and earthquakes in a horizontal range of $350-400 \mathrm{~km}$ around the sensor $(\mu \mathrm{S} / \mathrm{cm})$ within the marine environment. 
ferences among data series with an ascending tendency and descending tendency of the natural conductivity behavior records, equally within the continental and marine environments too, both sets of data were graphic analyzed initially according the total earthquakes occurred in each distance range above mentioned (Figure 34 \& Figure 35 and Table $1 \&$ Table 2 to site CAW01 and Figure 36 \& Figure 37 and Table $3 \&$ Table 4 to site CAW02); in complement, to find out significant statistical differences among data, to the data series, the Fisher test was applied (Figure 38 \& Figure 39 to site CAW01 and Figures 40-43 to site CAW02). The purpose of these last analysis aims to provide indirectly, evidence of the possible presence of energy flows in the surroundings previous to seismic activity and its possibly influence of natural water conductivity, effect probably related to the internal dynamics of the Earth's deep layers linked with natural voltage and electromagnetic energy pulses that reach the surface by lithosphere fractures, pulses that could trigger the slight seismic activity within the study area [10] [18] [19] [36] [41] [42] [43].

Within de study area, in the range of 0 to 50 kilometers, considered the most important range in terms of correlation between water natural conductivity $(\mu \mathrm{S} / \mathrm{cm})$ and seismic activity, the main characteristics of the earthquakes used in this research, correspond to micro-events to slight events $(<4.5 \mathrm{Mw})$ and almost all are classified shallow ( $<70 \mathrm{~km}$ depth) and just two was intermediates (72 and $80 \mathrm{~km}$ depth) occurred to 21 and 28 kilometers far away from the sensor.

\section{Discussion}

According to the accomplishment obtained, the study area call "Corralero" within the Pinotepa National municipality, demonstrate to be an area where the major quantity of earthquakes occur [35] [36]; in a range of 50 kilometers around, this statement is unobjectionable (Figure 1, Tables 1-4 and Figure 18), beyond of this range, the number of earthquakes occurred drops outstandingly.

\subsection{Variation of Natural Conductivity of Water and Trends}

Concerning the monitoring period in the site CAW01, from 03-February 2015 to 09 -March 2015 was a conductivity variation range of data of 700 to $800 \mu \mathrm{S} / \mathrm{cm}$, but thereafter the data series sustained an ascending trend from 700 to 1100 $\mu \mathrm{S} / \mathrm{cm}$ (March 09, 2015 to March 28, 2015), afterwards the tendency of data was descending 1100 to 750 (March, 282015 to April 15, 2015, end of monitoring), Figure 2.

Related to monitoring period in the site CAW02, from May 11, 2015 to June 15,2015 was a conductivity variation range of data of 650 to $800 \mu \mathrm{S} / \mathrm{cm}$ with two little periods with ascending and descending trend of data series. But from June15, 2015 to June22, 2015 the data series sustained an ascending trend from 650 to $1510 \mu \mathrm{S} / \mathrm{cm}$, thereafter from June 22, 2015 to July10, 2015 the data series' tendency was from 1510 to $650 \mu \mathrm{S} / \mathrm{cm}$, and again a new conductivity variation was observed with data ascending trend from 650 to $1520 \mu \mathrm{S} / \mathrm{cm}$, Figure 18 . 


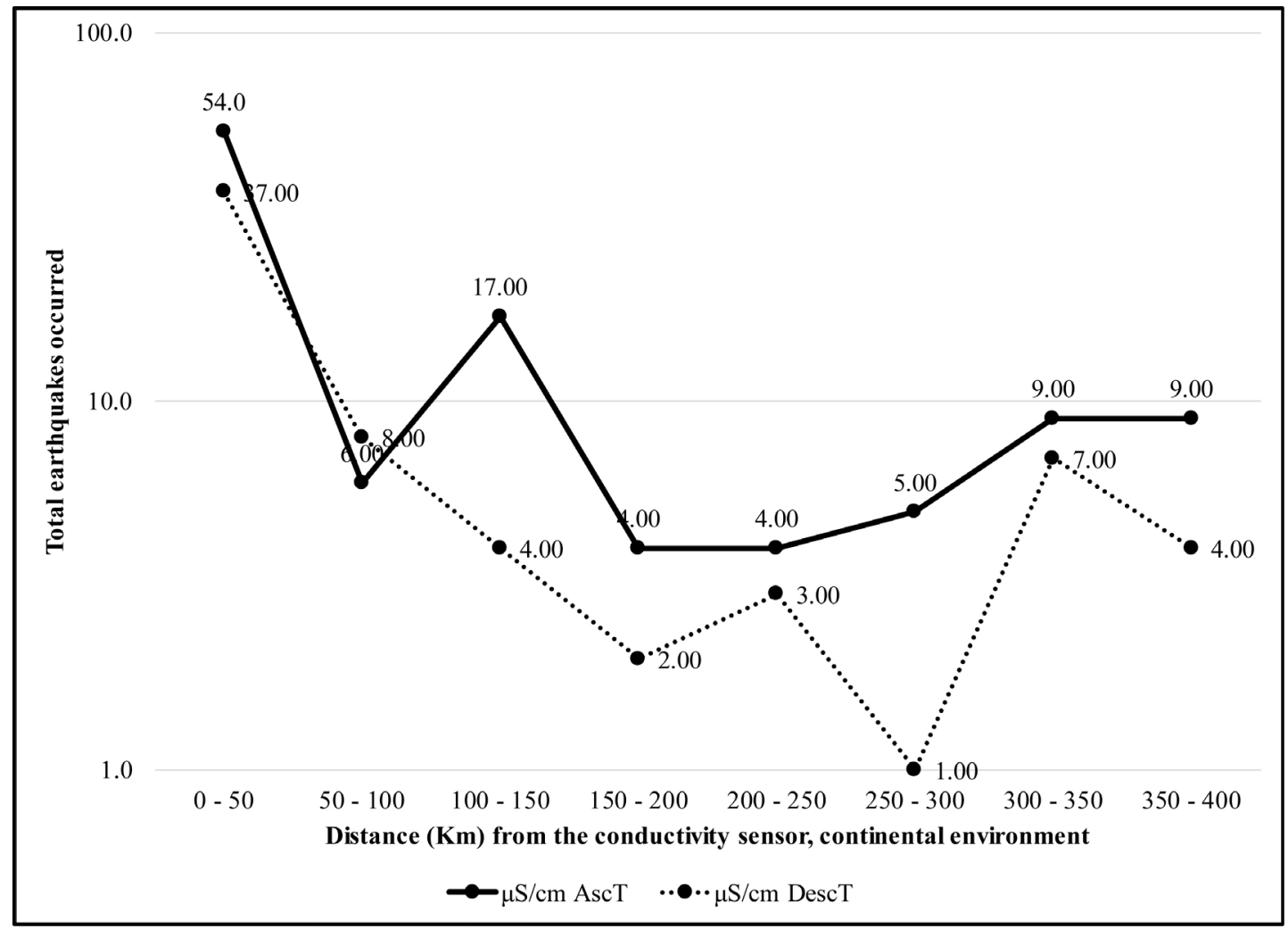

Figure 34. Site CAW01: Seismic activity variation to different range distance within continental environment.

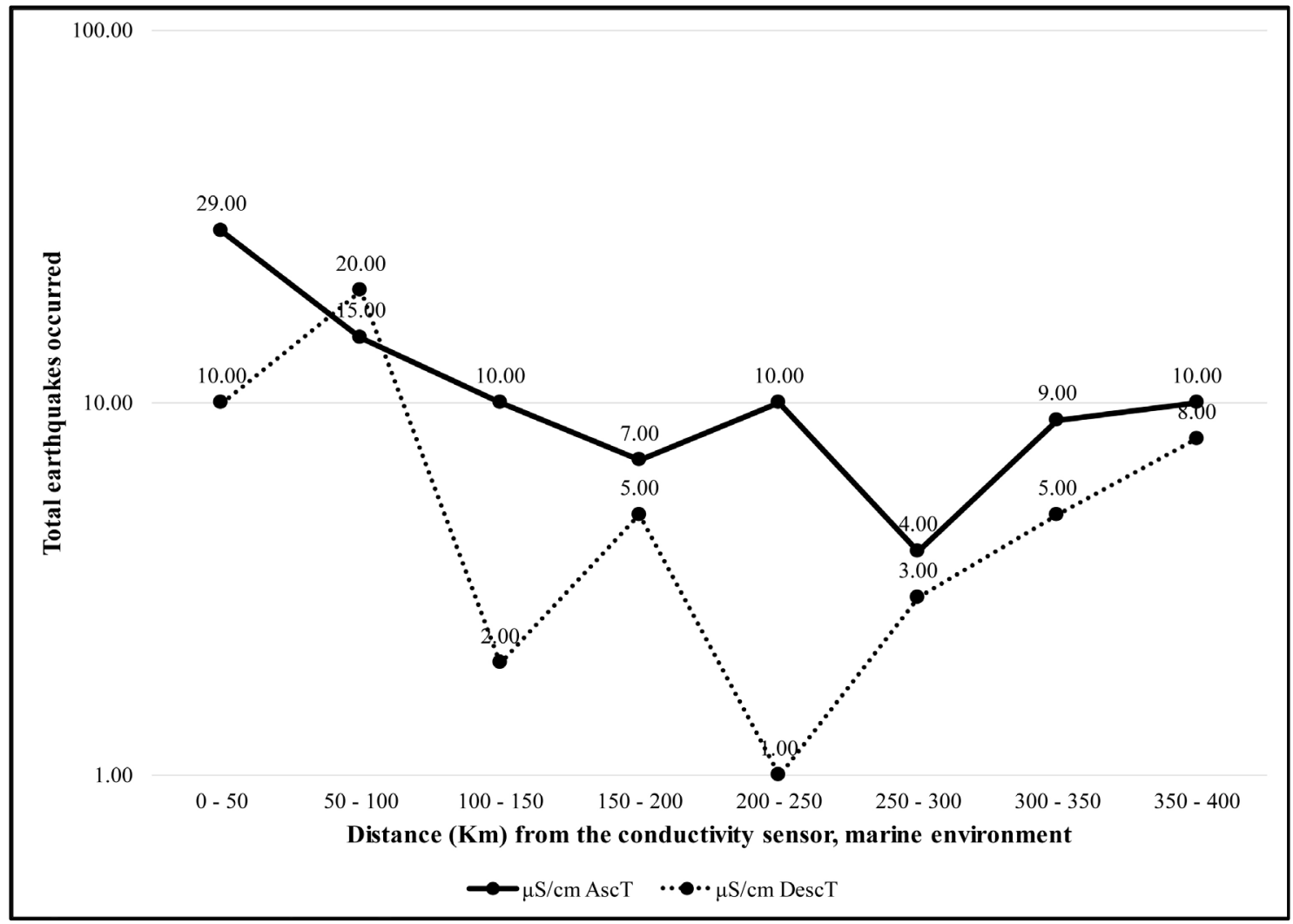

Figure 35. Site CAW01: Seismic activity variation to different range distance within marine environment. 


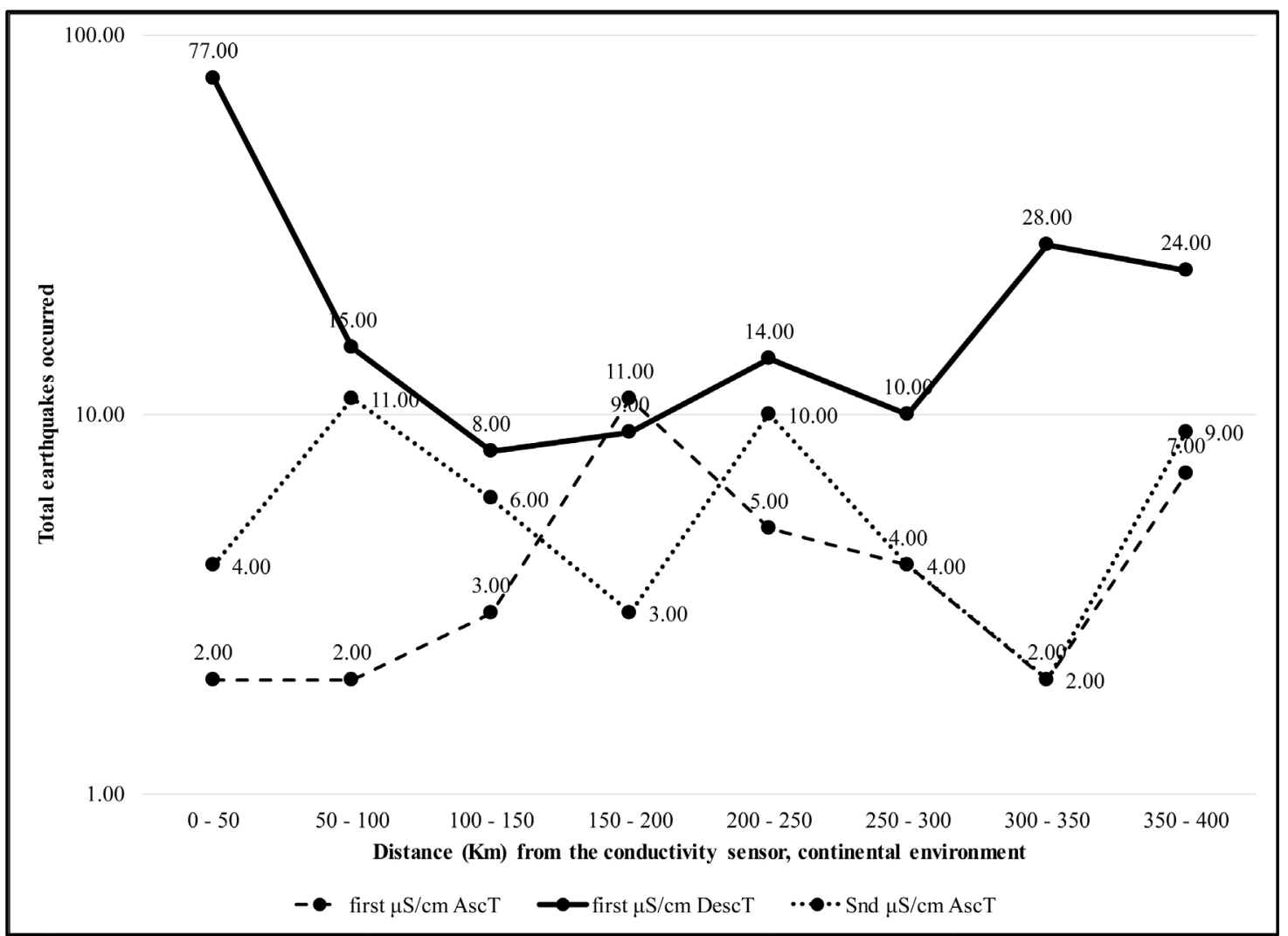

Figure 36. Site CAW02: Seismic activity variation to different range distance within continental environment.

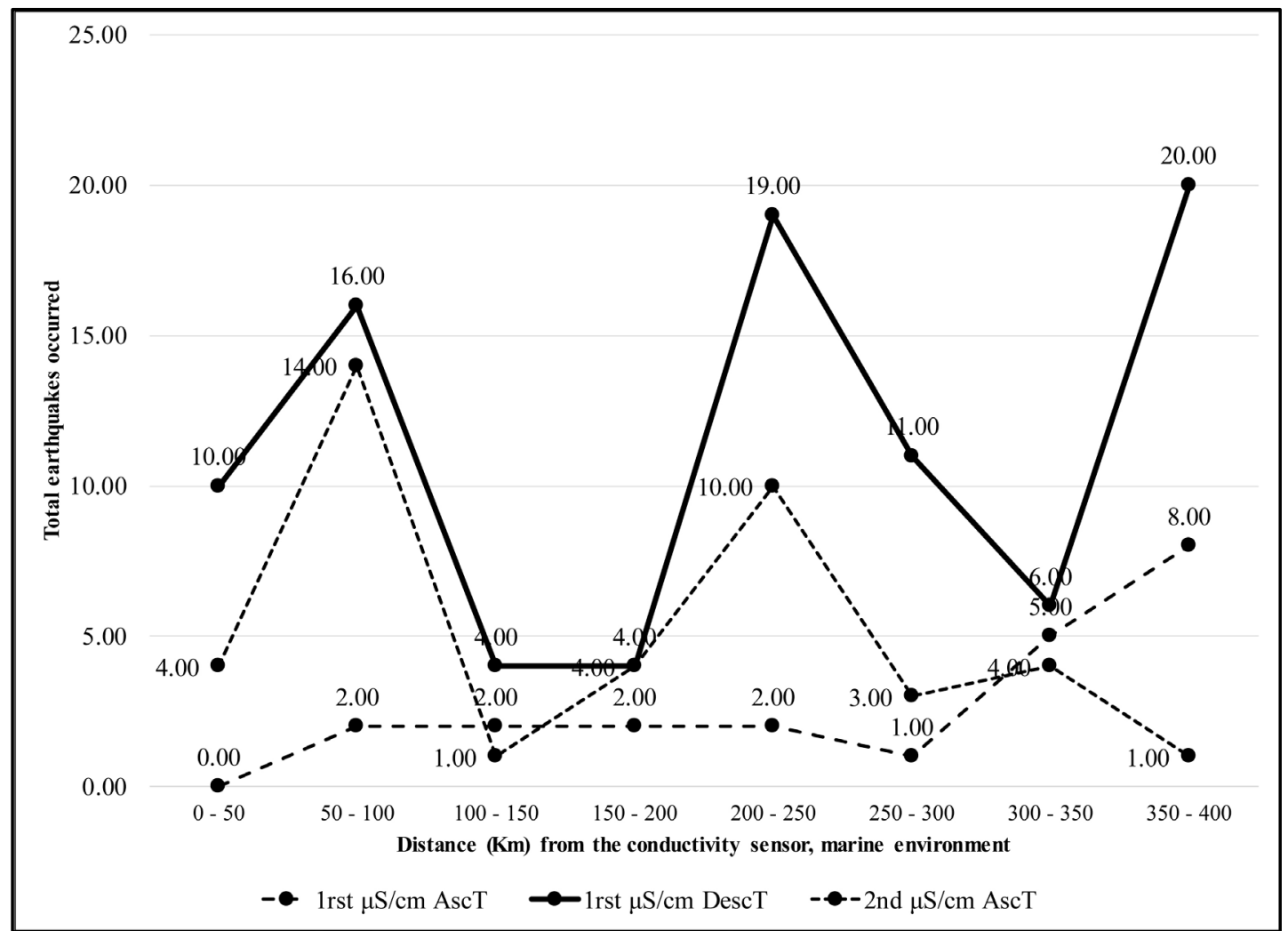

Figure 37. Site CAW02: Seismic activity variation to different range distance within marine environment. 
Table 1. Site CAW01: Data conductivity trend against EQ occurred to different distance ranges from conductivity sensor within continental environment.

\begin{tabular}{ccc}
\hline \multicolumn{3}{c}{ Total Events Occurred in Continental Environment } \\
\hline Range (Km) & Data conductivity tendency $(\mu \mathrm{S} / \mathrm{cm})$ \\
\cline { 2 - 3 } & 1 rst AscT & 1 rst DescT \\
\hline $50-50$ & 54 & 37 \\
$100-150$ & 6 & 8 \\
$150-200$ & 17 & 4 \\
$200-250$ & 4 & 2 \\
$250-300$ & 4 & 3 \\
$300-350$ & 5 & 1 \\
$350-400$ & 9 & 7 \\
\hline
\end{tabular}

AscT $=$ ascendant tendency; DescT $=$ Descendant tendency.

Table 2. Site CAW01: Data conductivity trend against EQ occurred to different distance ranges from conductivity sensor within marine environment.

\begin{tabular}{ccc}
\hline \multicolumn{3}{c}{ Total Events Occurred in Marine Environment } \\
\hline Range $(\mathrm{Km})$ & Data conductivity tendency $(\mu \mathrm{S} / \mathrm{cm})$ \\
\hline $0-50$ & 1 rst AscT & 1 rst DescT \\
$50-100$ & 29 & 10 \\
$100-150$ & 15 & 20 \\
$150-200$ & 10 & 2 \\
$200-250$ & 7 & 5 \\
$250-300$ & 10 & 1 \\
$300-350$ & 4 & 3 \\
$350-400$ & 9 & 5 \\
\hline
\end{tabular}

Asc $\mathrm{T}=$ ascendant tendency; Desc $\mathrm{T}=$ Descendant tendency.

Table 3. Site CAW02: Data conductivity trend against EQ occurred to different distance ranges from conductivity sensor within continental environment.

\begin{tabular}{cccc}
\hline \multicolumn{4}{c}{ Total Events Occurred in Continental Environment } \\
\hline Range $(\mathrm{Km})$ & \multicolumn{2}{c}{ Data Conductivity tendency $(\mu \mathrm{S} / \mathrm{cm})$} \\
\cline { 2 - 4 } & 2 & 1 1rst DescT & 2 nd AscT \\
\hline $50-50$ & 2 & 77 & 4 \\
$100-150$ & 3 & 15 & 11 \\
$150-200$ & 11 & 8 & 6 \\
$200-250$ & 5 & 9 & 3 \\
$250-300$ & 4 & 14 & 4 \\
$300-350$ & 2 & 10 & 2 \\
$350-400$ & 7 & 28 & 9 \\
\hline
\end{tabular}

AscT $=$ ascendant tendency; DescT $=$ Descendant tendency. 
Table 4. Site CAW02: Data conductivity trend against EQ occurred to different distance ranges from conductivity sensor within marine environment.

\begin{tabular}{|c|c|c|c|}
\hline \multicolumn{4}{|c|}{ Total Events Occurred in Marine Environment } \\
\hline \multirow{2}{*}{ Range (Km) } & \multicolumn{3}{|c|}{ Data conductivity tendency $(\mu \mathrm{S} / \mathrm{cm})$} \\
\hline & 1rst AscT & 1rst DescT & 2nd AscT \\
\hline $0-50$ & 0 & 10 & 4 \\
\hline $50-100$ & 2 & 16 & 14 \\
\hline $100-150$ & 2 & 4 & 1 \\
\hline $150-200$ & 2 & 4 & 4 \\
\hline $200-250$ & 2 & 19 & 10 \\
\hline $250-300$ & 1 & 11 & 3 \\
\hline $300-350$ & 5 & 6 & 4 \\
\hline $350-400$ & 8 & 20 & 1 \\
\hline
\end{tabular}

$\mathrm{Asc} \mathrm{T}=$ ascendant tendency; Desc $\mathrm{T}=$ Descendant tendency.

5.00
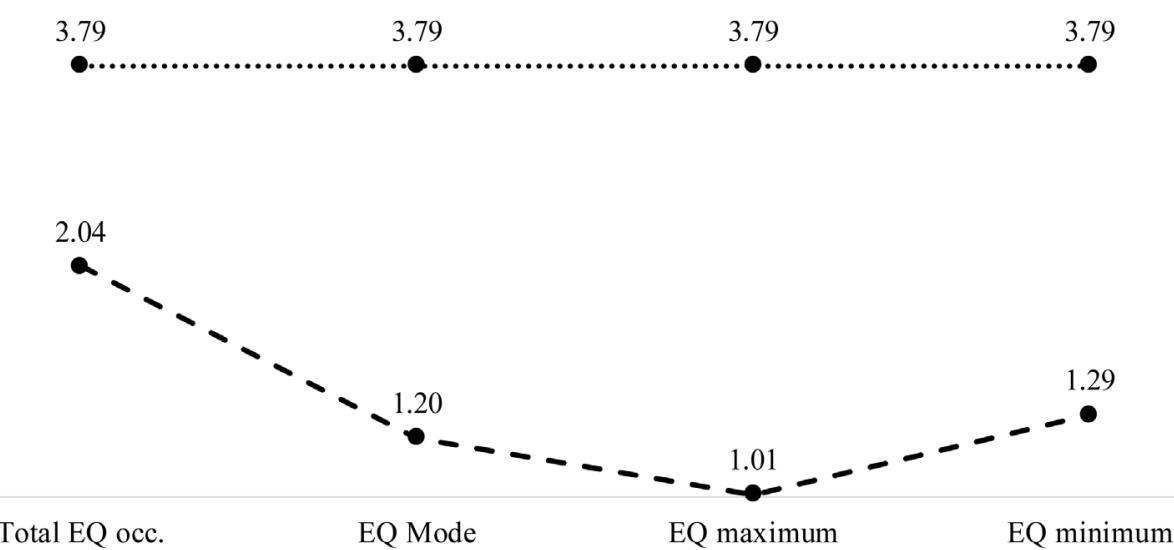

0.50

\section{Fisher Test ....Fisher Critic Value}

Figure 38. Significant statistical differences of seismic activity within continental environment: Site CAW01 data analysis (first descendent trend against first ascendant trend). 


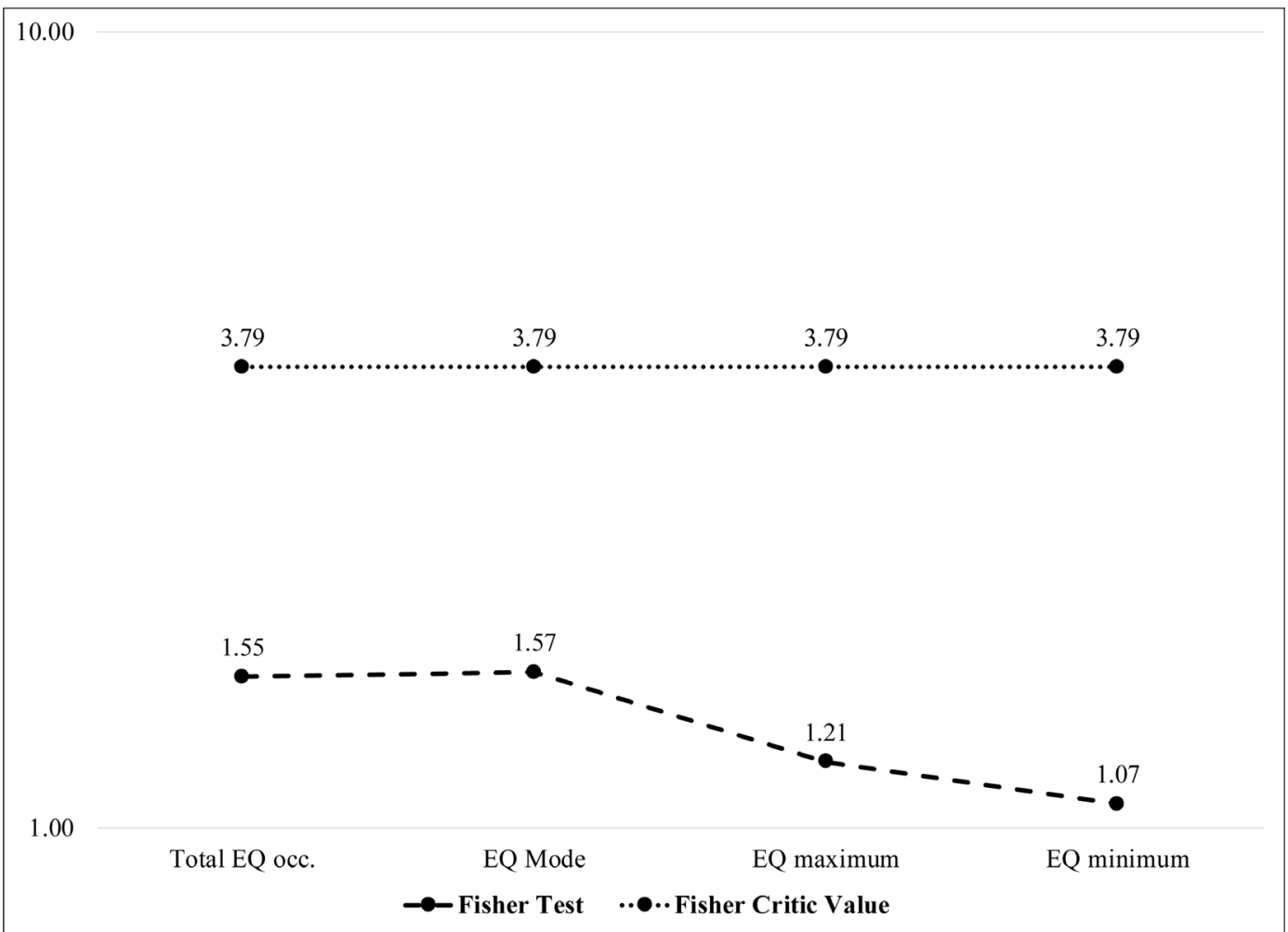

Figure 39. Significant statistical differences of seismic activity within marine environment: Site CAW01 data analysis (first descendent trend against first ascendant trend).

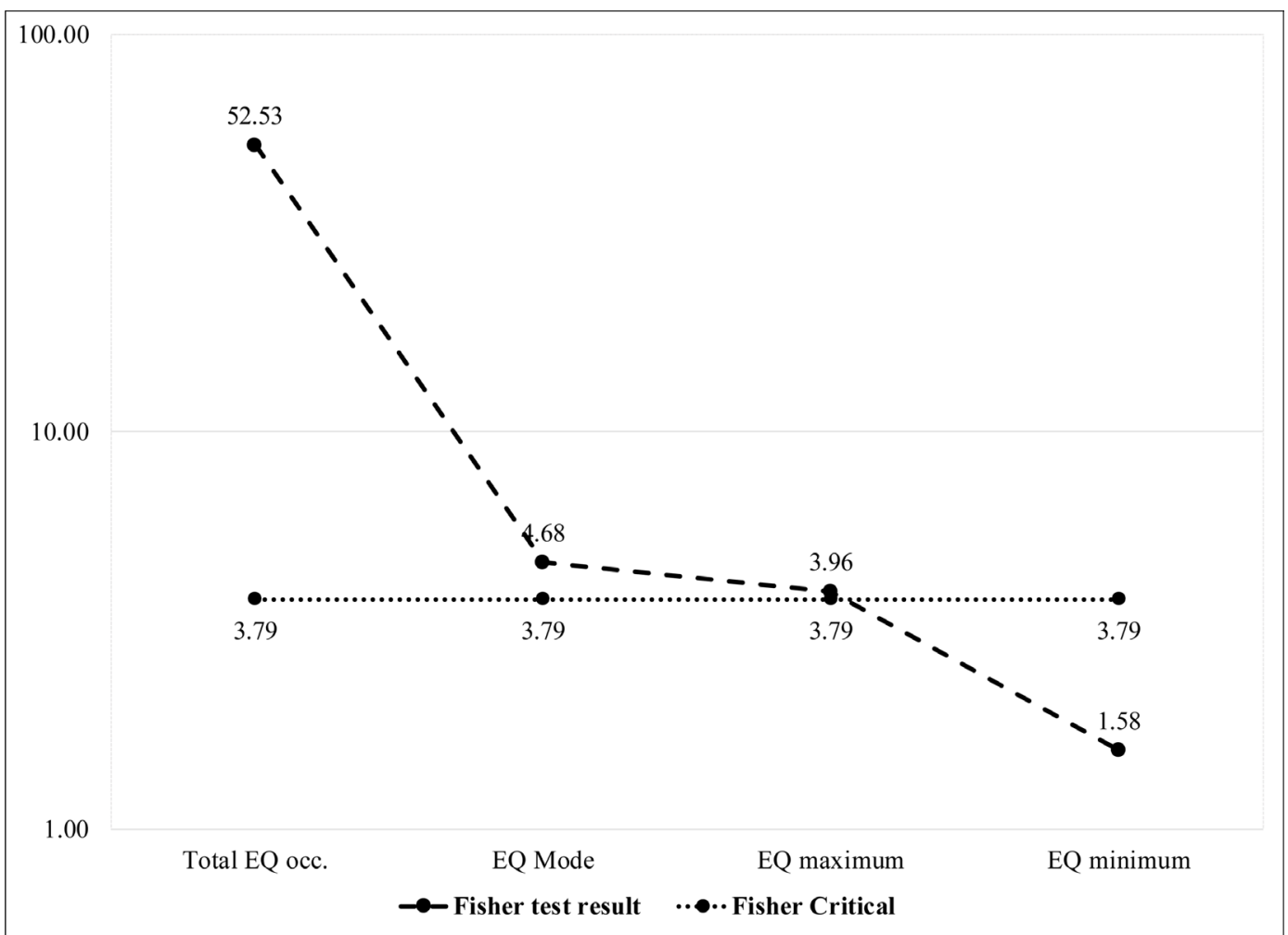

Figure 40. Significant statistical differences of seismic activity within continental environment: Site CAW02 data analysis (first descendent trend against first ascendant trend). 


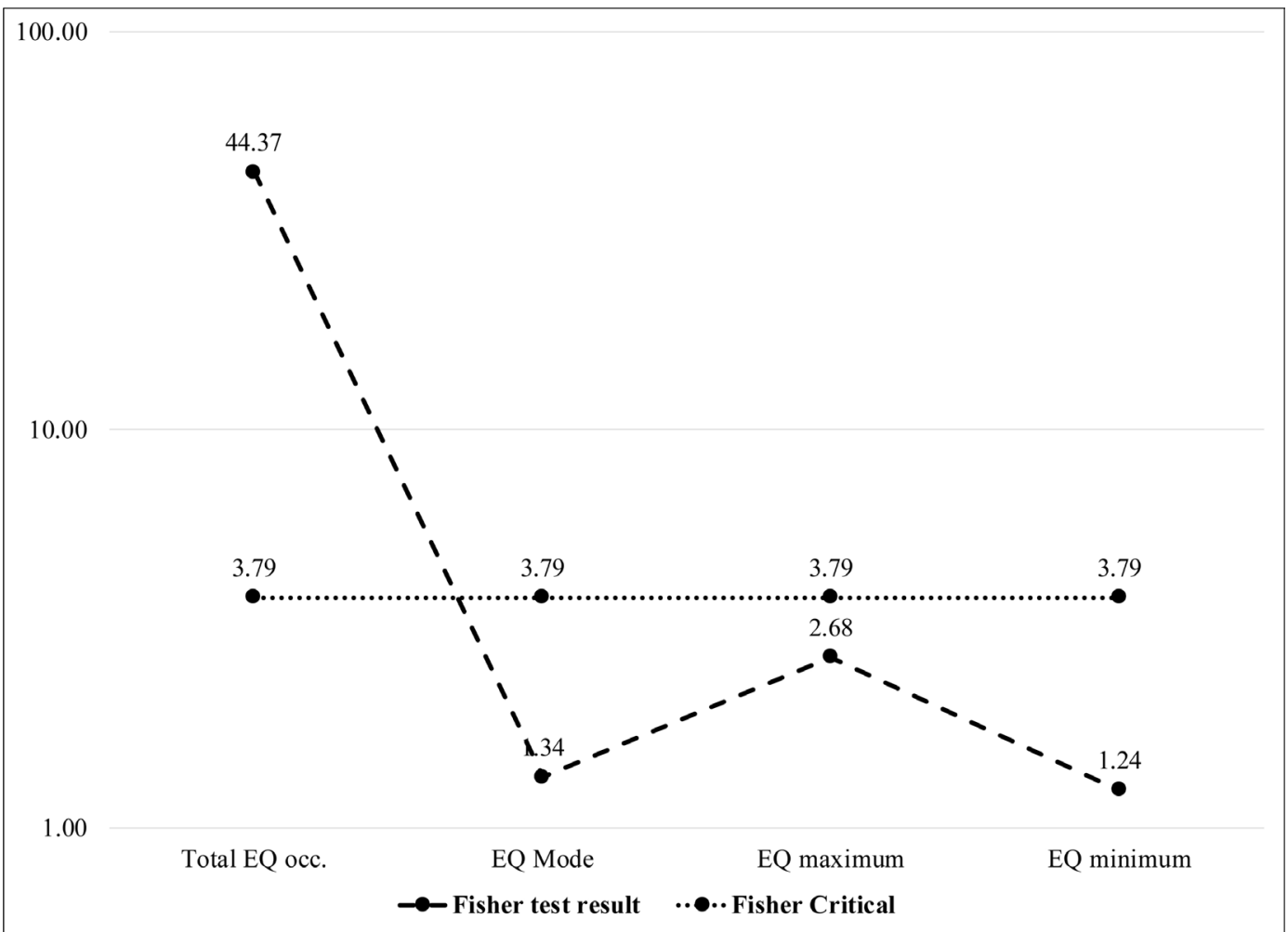

Figure 41. Significant statistical differences of seismic activity within continental environment: Site CAW02 data analysis (first descendent trend against second ascendant trend).

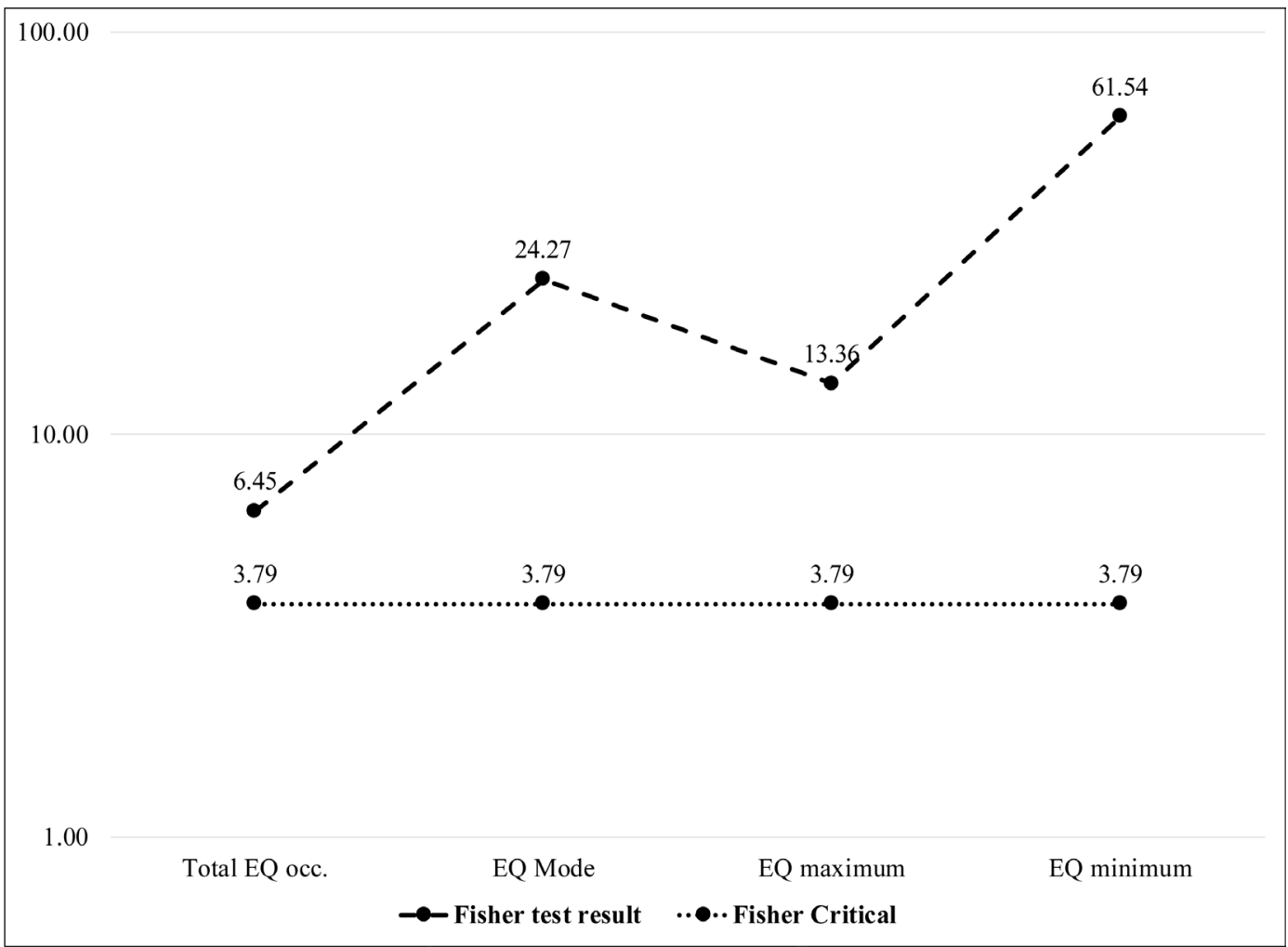

Figure 42. Significant statistical differences of seismic activity within marine environment: Site CAW02 analysis of data (first descendent trend against first ascendant trend). 


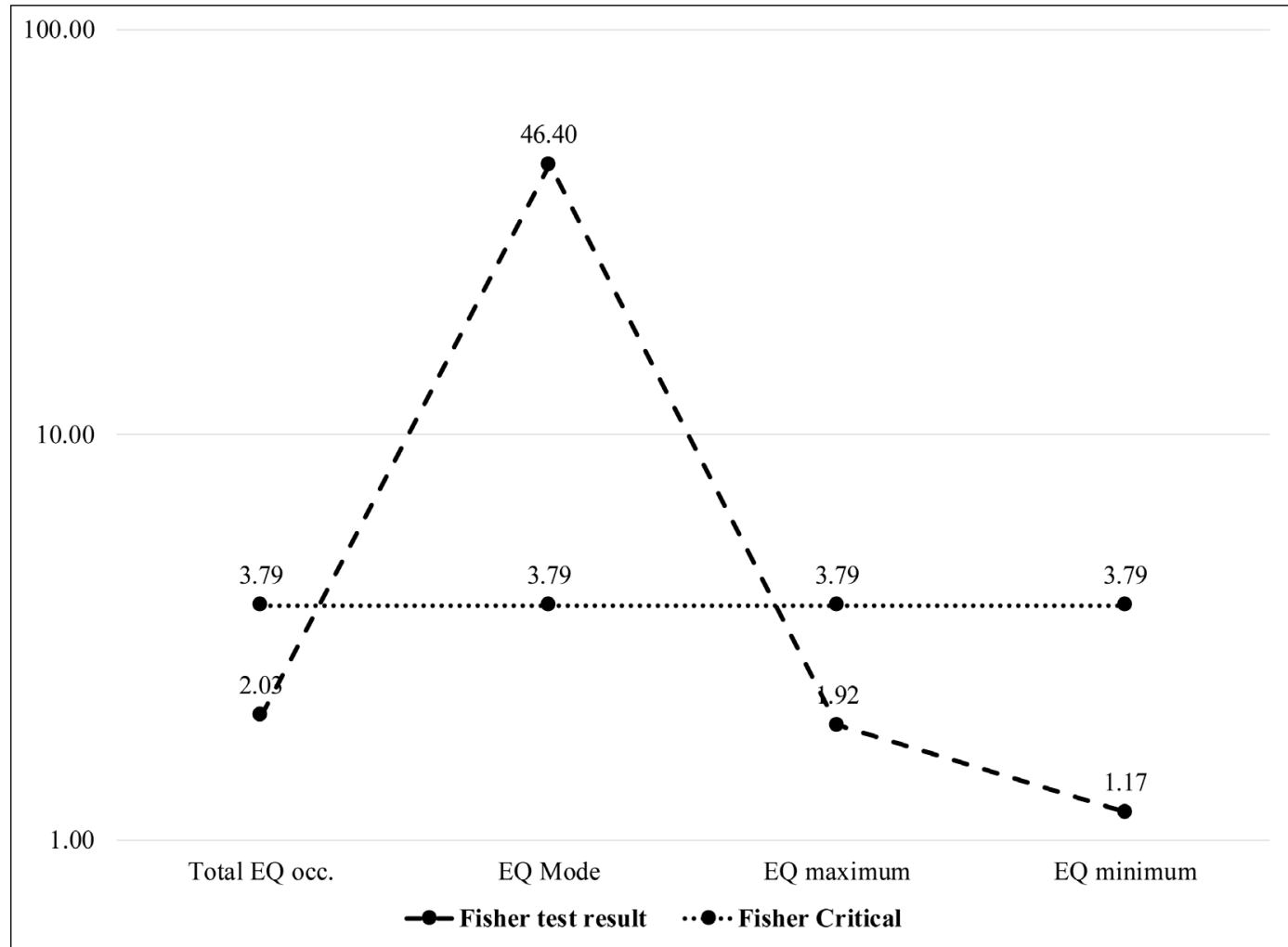

Figure 43. Significant statistical differences of seismic activity within marine environment: Site CAW02 analysis of data (first descendent trend against second ascendant trend).

\subsection{Trends of Natural Conductivity of Water and the Earthquakes Occurred}

Between the sites CAW01 and CAW02 there were some remarkable differences that highlights the possible correlation among the trends of natural conductivity of water and the earthquakes occurred in the same period when analyzed to distance range of 50,100,150,200, 250, 300, 350 and 400 kilometers far away of the sensor, Figures 1-33.

With regard to the number of earthquakes versus trends of water natural conductivity records between both wells, the range of distance nearest with more events was of 0 to $50 \mathrm{~km}$. In the site CAW01 according to the periods of ascending and descending of conductivity data series above described, the analysis of records in the continental and marine environments show the next characteristics. According to Table 1, in the continental environment, Figure 34, during the first ascending tendency of data series occurred 54 seismic events within the range of 0 to $50 \mathrm{~km}$; subsequently, the number of events decreased noticeably to 9 in the last range of 350 to 400 kilometers. With reference to the first period of descending tendency of data series only occurred 37 seismic events but thereafter the number of events decreased dramatically, only 4 events occurred on average over the following distance ranges.

Agreeing with the Table 2, the data behavior of CAW01 within the marine environment, Figure 35, showed that in the first ascending trend of data series 
occurred 29 seismic events within the range of 0 to $50 \mathrm{~km}$ with an average of 9 events in the remaining ranges. In the case of the period of first descending tendency of data series only occurred few seismic events starts with 10 and 20 events within the range of 0 to $50 \mathrm{~km}$ and 50 to $100 \mathrm{~km}$, but again decreases with an average of 4 events in the next ranges.

In the case of the Site CAW02, as described before (subsection 5.1), in conformity to Table 3 , the behavior of the natural conductivity data was quite atypical with important oscillations; in the continental environment, Figure 36, the first notable period of ascending tendency of data series had an average of 5 events with a peak of 11 in the range of 150 to $200 \mathrm{~km}$. The first period with descending trend of data series had 77 seismic events in range of 0 to $50 \mathrm{~km}$, with an average of 16 events in the last ranges. The second series data with ascending tendency had 4 events in the range of 0 to $50 \mathrm{~km}$ and three peaks of 11 , 10 and 9 events in the corresponding ranges of 50 to 100,200 to 250 and 350 to $400 \mathrm{~km}$.

In correspondence of Table 4 content, referring to the observed in the marine environment, the first period of ascending tendency of data series had an average of 3 events; the next period of descending tendency of data series had an average of 11 events with two peaks of 19 and 20 corresponding to the ranges 200 to 250 and 350 to $400 \mathrm{~km}$. The last period with ascending tendency in the data series had an average of 5 events with a peak of 14 events in the range of 50 to $100 \mathrm{~km}$, Figure 37.

\subsection{Significant Statistical Differences of Data}

Both conductivity data series maintained similar behavior trends regardless of whether the data is from site CAW01 (period from March 09, 2015 to April 15, 2015, Figures 2-17) or CAW02 (period from June 15, 2015 to July 10, 2015, Figures 18-33), but in terms of the possible correlation in each range of distance, between the conductivity records and the subsequent micro-seismic activity, it was substantially different when they are face up, and the role of environmental local conditions (continental and marine) was very important; these differences were more evident when obtaining the results of the application of the statistical significance of the data (natural water conductivity versus seismic activity).

The statistical analysis applying the Fisher test to the CAW01 and Site CAW02s in both environments, continental and marine, involved several important aspects as the total earthquakes occurred (Total EQ occ.), the mode earthquakes ( $E Q$ Mode), the earthquakes maximum or with more intensity and the earthquakes minimum or with less intensity (EQ maximum - EQ minimum). For the Site CAW01 there were no significant statistical differences between the periods of first ascending and first descending of data series, the behavior of data were very similar in the continental and marine environment, Figure 38 and Figure 39. The reasons could be related to the proximity of the monitoring site 
with nearby coastal bodies of water, the influence of recharge and voluminous water mixtures (ions dilution) can mean an important interference, no doubt that effect is magnified even more with the analysis of data series within marine environment.

The accomplishments in the CAW02 statistical analysis showed a significant statistical difference among the three different important oscillations of conductivity records, Figure 40 and Figure 41, particularly within the continental environment. According to the total earthquakes occurred (Total EQ occ.), the range of 0 to $50 \mathrm{Km}$ showed the most important statistical significance, such as seen in the first descending period against first ascending period of data series, Figures 18-25, revealing the most number of earthquakes, the mode higher and earthquakes with more intensity, Figure 36 \& Figure 37, Table 3 \& Table 4 and Figure 40. In the case of first descending period against $2^{\text {nd }}$ ascending period of data series there was statistical significance only in the total earthquakes occurred (Total EQ occ.), Figure 41. It seems that the observed behavior is possibly resulted of the local conditions related to the physical environment, which are characterized by a setting with a higher temperature in relation to the surrounding environment, $30 \%$ more [44], also is settled in a region with a complex tectonic history of magmatism and metamorphism, also the regional continental crust is probably highly fractured [37].

In the marine environment again it was manifest the significant statistical differences among the total earthquakes occurred and the mode earthquakes (the earthquakes with more intensity and the earthquakes with less intensity), when it is compared the first descending period of data against first ascending period of data series applied in range of 0 to $50 \mathrm{~km}$, Figure 42 . Related to second ascending period of data series against first descending period there were statistical significances only in the value most frequent of earthquakes (mode), regularly events with more intensity, Figure 43.

\section{Conclusions}

In a range of 50 kilometers round, the study area called "Corralero" within the Pinotepa National municipality, Oaxaca State, demonstrates to be an area where the major quantity of earthquakes occur, Figure $1 \&$ Figure 2, Figure 18, Figure 34 and Figure 36. Correspond to micro-events to slight events $(<4.5 \mathrm{Mw})$ and $98 \%$ are considered shallow manifested to $<70 \mathrm{~km}$ depth and just one was intermediate with $72 \mathrm{~km}$ depth.

The spatial position of each well (CAW01 and Site CAW02) was decisive and determinant in the grade of influence of surrounding environment, and these effects can be related to the presence of aquatic environment and dynamic water mixing that affect the ions dissolved, this relationship is very clear in the conductivity behavior data recorded in Site CAW01 for closeness of coastal bodies of water. In this case, there were no significant statistical differences between data series, and the behavior was very similar in the continental and marine en- 
vironment.

However, in the case of site CAW02, the influence of surrounding environment related to lithological barriers and regional and local stratigraphic units, affects different in the regional and local hydrological dynamics, so the water conductivity behavior data recorded in the site CAW02 is influenced possibly by local lithological and stratigraphic conditions, region that has a complex tectonic history of magmatism and metamorphism, with many discontinuities or weakness zones, because possibly the local crust is highly fractured [37]. Seemingly these surrounding environment conditions caused significant statistical differences among the main oscillations of conductivity records above described and possibly promote the slight seismic activity too [11] [41] [45] [46] [47] [48]. According to that, in general, within the continental environment, the range of 0 to $50 \mathrm{~km}$ showed the most important statistical significance, revealing to have the most number of earthquakes, Figure 40 \& Figure 41, with higher values and more intensity, particularly when the tendency of conductivity data is descending. A very similar connection within the marine environment between the conductivity data behavior and seismic activity occurred during recording time was observed.

This research developed in the seismic coastal border limits of Guerrero-Oaxaca states, Mexico, was worked out with the intention of strengthening more in the knowledge of the previous events on the earthquakes and the possible connection between natural voltage and electromagnetic energy emanating from the inner layers of the Earth. Therefore, the data of natural water conductivity analyzed in this research seems to support this linkage taking in account the behavior of each conductivity record and the time trends; according to the results, the natural water conductivity data and more important trends recorded in the study area give the impression that occur before the seismic activity, Figures 18-25 and Table 3 \& Table 4.

\section{Acknowledgements}

The author enthusiastically acknowledge the contributions to this research to Engineer José Francisco Hernández Pérez, Head of the Center of Proposed Draft of the South Pacific, regional office of the Coordination of Hydroelectric Projects (Federal Electricity Commission), for the logistic support, transportation, human and financial resources provided, without this decisive help would have been extremely difficult for ending this research. In the same way to Dr. Arturo Colín Cruz from the Faculty of Chemistry, Autonomous University of Mexico State, Toluca de Lerdo, Mexico, for his invaluable experience and professional guidance. Finally, to Andrés Suasto A. and Oscar E. González A, for their support, friendship and solidarity during the trips.

\section{References}

[1] Liu, J.Y, Chuo, Y.J., Shan, S.J., et al. (2004) Pre-Earthquake Ionospheric Anomalies Registered by Continuous GPS TEC Measurements. Annals of Geophysics, 22, 
1585-1593. https://doi.org/10.5194/angeo-22-1585-2004

[2] Pulinets, S. (2004) Ionospheric Precursors of Earthquakes: Recent Advances in Theory and Practical Applications. Terrestrial Atmospheric and Oceanic Sciences, 15, 413-435. https://doi.org/10.3319/TAO.2004.15.3.413(EP)

[3] Namgaladze, A.A., Zolotov, O.V., Karpov, M.I. and Romanovskaya, YV. (2012) Manifestations of the Earthquake Preparations in the Ionosphere Total Electron Content Variations. Natural science, 4, 848-855. https://doi.org/10.4236/ns.2012.411113

[4] Le, H., Liu, L., Liu, J.Y., Zhao, B., Chen, Y. and Wan, W. (2013) The Ionospheric Anomalies Prior to the M9.0 Tohoku-Oki Earthquake. Journal of Asian Earth Sciences, 62, 476-484. https://doi.org/10.1016/j.jseaes.2012.10.034

[5] Athanasiou, M.A., Anagnostopoulos, G.C., David, C.N. and Machairidis, G.G. (2014) The Ultra Low Frequency Electromagnetic Radiation Observed in the Topside Ionosphere Above Boundaries of Tectonic Plates. Research in Geophysics, 4, 31-39.

[6] Liu, J., Huang, J. and Zhang, X. (2014) Ionospheric Perturbations in Plasma Parameters before Global Strong Earthquakes. Advances in Space Research, 53, 776-787. https://doi.org/10.1016/j.asr.2013.12.029

[7] Liperovskaya, E.V., Meister, C., Hoffmann, D.H.H., Silina, A.S. and Vasil, N.E. (2015) On the Diurnal Dependence of $\mathrm{f} \mathrm{b} \mathrm{E} \mathrm{s} \mathrm{-Variations} \mathrm{Due} \mathrm{to} \mathrm{Earthquakes.} \mathrm{In-}$ ternational Journal of Geosciences, 6, 656-665. https://doi.org/10.4236/ijg.2015.67053

[8] Pulinets, S.A. (2009) Physical Mechanism of the Vertical Electric Field Generation over Active Tectonic Faults. Advances in Space Research, 44, 767-773.

https://doi.org/10.1016/j.asr.2009.04.038

[9] Dunajecka, M.A. and Pulinets, S.A. (2005) Atmospheric and Thermal Anomalies Observed around the Time of Strong Earthquakes in Mexico. Atmosfera, 18, 235-247.

[10] Cicerone, R.D., Ebel, J.E. and Britton J. (2009) A Systematic Compilation of Earthquake Precursors. Tectonophysics, 476, 371-396.

https://doi.org/10.1016/j.tecto.2009.06.008

[11] Freund, F.T. (2003) Rocks that Crackle and Sparkle and Glow: Strange Pre-Earthquake Phenomena. Journal of Scientific Exploration, 17, 37-71.

[12] Koren, I., Altaratz, O., Remer, L.A., Feingold, G., Martins, J.V. and Heiblum, R.H. (2012) Aerosol-Induced Intensification of Rain from the Tropics to the Mid-Latitudes. Nature Geoscience, 5, 118-122. https://doi.org/10.1038/ngeo1364

[13] Kawaguchi, Y. (1998) Charged Particle Emission and Luminescence upon Bending Fracture of Granite. The Japanese Journal of Applied Physics, 37, 3495-3499. https://doi.org/10.1143/JJAP.37.3495

[14] Fidani, C. (2010) The Earthquake Lights (EQL) of the 6 April 2009 Aquila Earthquake, in Central Italy. Natural Hazards and Earth System Sciences, 10, 967-978. https://doi.org/10.5194/nhess-10-967-2010

[15] Heraud, J.A. and Lira, J.A. (2011) Co-Seismic Luminescence in Lima, $150 \mathrm{~km}$ from the Epicenter of the Pisco, Peru Earthquake of 15 August 2007. Natural Hazards and Earth System Sciences, 11, 1025-1036.

https://doi.org/10.5194/nhess-11-1025-2011

[16] Whitehead, N.E. and Ulusoy, Ü. (2015) Origin of Earthquake Light Associated with Earthquakes in Christchurch, New Zealand, 2010-2011. Earth Science Research 
Journal, 19, 113-120. https://doi.org/10.15446/esrj.v19n2.47000

[17] Silva, H.G., Bezzeghoud, M., Reis, A.H., et al. (2011) Atmospheric Electrical Field Decrease during the $\mathrm{M}=4.1$ Sousel Earthquake (Portugal). Natural Hazards and Earth System Sciences, 11, 987-991. https://doi.org/10.5194/nhess-11-987-2011

[18] Asada, T., Baba, H., Kawazoe, M. and Sugiura, M. (2001) An Attempt to Delineate Very Low Frequency Electromagnetic Signals Associated with Earthquakes. Earth, Planets and Space, 53, 55-62. https://doi.org/10.1186/BF03352362

[19] Bleier, T., Dunson, C., Alvarez, C., Freund, F. and Dahlgren, R. (2010) Correlation of Pre-Earthquake Electromagnetic Signals with Laboratory and Field Rock Experiments. Natural Hazards and Earth System Sciences, 10, 1965-1975. https://doi.org/10.5194/nhess-10-1965-2010

[20] Guo, G. and Wang, B. (2008) Cloud Anomaly before Iran Earthquake. International Journal of Remote Sensing, 29, 1921-1928. https://doi.org/10.1080/01431160701373762

[21] Guo, G. and Jie, Y. (2013) Three Attempts of Earthquake Prediction with Satellite Cloud Images. Natural Hazards and Earth System Sciences, 13, 91-95. https://doi.org/10.5194/nhess-13-91-2013

[22] Li, L.-X., Wu. J.-P. and Liu, S.-J. (2009) Space Observed Two Abnormal Linear Clouds before Wenchuan Earthquake. In: 3 rd IASME/WSEAS International Conference on Geology and Seismology, Cambridge, 24-26 February 2009, 138-143.

[23] Shou, Z. (2007) The Cloud of the m8.4 Indonesian Earthquake on September 12. New Concepts in Global Tectonics Newsletter, (45), 31-33.

[24] Buskirk, R.E., Frohlich, C. and Latham, G.V. (1981) Unusual Animal Behavior before Earthquakes: A Review of Possible Sensory Mechanisms. Reviews of Geophysics, 19, 247-270. https://doi.org/10.1029/RG019i002p00247

[25] Frohlich, C. and Buskirk, R.E. (1980) Can Fish Detect Seismic Waves? Geophysical Research Letters, 7, 569-572. https://doi.org/10.1029/GL007i008p00569

[26] Grant, R. A., Halliday, T., Balderer, W.P., et al. (2011) Ground water Chemistry Changes before Major Earthquakes and Possible Effects on Animals. International Journal of Environmental Research and Public Health, 8, 1936-1956. https://doi.org/10.3390/ijerph8061936

[27] Grant, RA. and Halliday, T. (2010) Predicting the Unpredictable Evidence of Pre-Seismic Anticipatory Behaviour in the Common Toad. Journal of Zoology, 281, 263-271. https://doi.org/10.1111/j.1469-7998.2010.00700.x

[28] Hallett, M. (1992) Perception of the Pre-Seismic Signals among Reptiles. The Case of the Parma Apennines (Italy). New Concepts in Global Tectonics Newsletter, 15, 1106-1107.

[29] Kirschvink, J.L. (2000) Earthquake Prediction by Animals: Evolution and Sensory Perception. Bulletin of the Seismological Society of America, 90, 312-323. https://doi.org/10.1785/0119980114

[30] Lighton, J.R.B. and Duncan, F.D. (2005) Shaken, Not Stirred: A Serendipitous Study of Ants and Earthquakes. Journal of Experimental Biology, 208, 3103-3107. https://doi.org/10.1242/jeb.01735

[31] Athanasiou, M.A., Anagnostopoulos, G.C., Iliopoulos, A.C., Pavlos, G.P. and David, C.N. (2011) Enhanced ULF Radiation Observed by DEMETER Two Months around the Strong 2010 Haiti Earthquake. Natural Hazards and Earth System Sciences, 11, 1091-1098. https://doi.org/10.5194/nhess-11-1091-2011

[32] Zhang, X., Shen, X., Parrot, M., et al. (2012) Phenomena of Electrostatic Perturba- 
tions before Strong Earthquakes (2005-2010) Observed on DEMETER. Natural Hazards and Earth System Sciences, 12, 75-83.

https://doi.org/10.5194/nhess-12-75-2012

[33] Walker, S.N., Kadirkamanathan, V. and Pokhotelov, O.A. (2013) Changes in the Ultra-Low Frequency Wave Field during the Precursor Phase to the Sichuan Earthquake : DEMETER Observations. Annals of Geophysics, 31, 1597-1603. https://doi.org/10.5194/angeo-31-1597-2013

[34] Li, M. and Parrot, M. (2013) Statistical Analysis of an Ionospheric Parameter as a Base for Earthquake Prediction. Journal of Geophysical Research, 118, 3731-3739. https://doi.org/10.1002/jgra.50313

[35] Martínez-García, F., Colín-Cruz, A., Adame-Martínez, S. and Ramírez-García, J.J. (2015) Atypical Variations of Water Conductivity Prior to Tectonic Earthquakes. International Journal of Geosciences, 6, 1367-1385. https://doi.org/10.4236/ijg.2015.612108

[36] Martínez-García, F., Colín-Cruz, A., Pereira-Corona, A., Adame-Martínez, S. and Ramírez-García, J.J. (2016) Natural Water Conductivity Behavior within the Seismic Pacific Coast of Southern Mexico. Open Access Library Journal, 3, e2836. https://doi.org/10.4236/oalib.1102836

[37] Yamamoto, J., González-Moran, T., Quintanar, L., Zavaleta, A.B., Zamora, A. and Espindola, V.H. (2013) Seismic Patterns of the Guerrero-Oaxaca, Mexico Region, and Its Relationship to the Continental Margin Structure. Geophysical Journal International, 192, 375-389. https://doi.org/10.1093/gji/ggs025

[38] Payero, J.S., Kostoglodov, V., Shapiro, N., et al. (2008) Nonvolcanic Tremor Observed in the Mexican Subduction Zone. Geophysical Research Letters, 35, 1-6. https://doi.org/10.1029/2007GL032877

[39] Obara, K. and Sekine, S. (2009) Characteristic Activity and Migration of Episodic Tremor and Slow-Slip Events in Central Japan. Earth, Planets and Space, 61, 853-862. https://doi.org/10.1186/BF03353196

[40] Chapin, T.P., Todd, A.S. and Zeigler, M.P. (2014) Robust, Low-Cost Data Loggers for Stream Temperature, Flow Intermittency, and Relative Conductivity Monitoring. Water Resources Research, 50, 5216-5234. https://doi.org/10.1002/2013WR015158

[41] Scoville, J., Heraud, J. and Freund, F. (2015) Pre-Earthquake Magnetic Pulses. Natural Hazards and Earth System Sciences, 15, 1873-1880.

https://doi.org/10.5194/nhess-15-1873-2015

[42] Freund, F. and Stolc, V. (2013) Nature of Pre-Earthquake Phenomena and Their Effects on Living Organisms. Animals, 3, 513-531. https://doi.org/10.3390/ani3020513

[43] Bleier, T., Dunson, C., Maniscalco, M., Bryant, N., Bambery, R. and Freund, F. (2009) Investigation of ULF Magnetic Pulsations, Air Conductivity Changes, and Infra-Red Signatures Associated with the 30 October Alum Rock M5.4 Earthquake. Natural Hazards and Earth System Sciences, 9, 585-603.

https://doi.org/10.5194/nhess-9-585-2009

[44] Menea, M. and Menea, V.C. (2010) Curie Point Depth Estimates and Correlation with Subduction in Mexico. Pure and Applied Geophysics, 168, 1489-1499. https://doi.org/10.1007/s00024-010-0238-2

[45] Shinbrot, T., Kim, N.H. and Thyagu, N.N. (2012) Electrostatic Precursors to Granular Slip Events. Proceedings of the National Academy of Sciences, 109, 10806-10810. https://doi.org/10.1073/pnas.1121596109 
[46] Daniels, K. E., Bauer, C. and Shinbrot, T. (2013) Correlations between Electrical and Mechanical Signals during Granular Stick-Slip Events. Granular Matter, 16, 217-222. https://doi.org/10.1007/s10035-013-0471-3

[47] Leeman, J.R., Scuderi, M.M., Marone, C., Saffer, D.M. and Shinbrot, T. (2014) Journal of Geophysical Research : Solid Earth On the Origin and Evolution of Electrical Signals during Frictional Stick Slip in Sheared Granular Material. Journal of Geophysical Research, 119, 4253-4268. https://doi.org/10.1002/2013JB010793

[48] Freund, F.T. (2007) Pre-Earthquake Signals-Part II: Flow of Battery Currents in the Crust. Natural Hazards and Earth System Sciences, 7, 543-548.

https://doi.org/10.5194/nhess-7-543-2007

Submit or recommend next manuscript to OALib Journal and we will provide best service for you:

- Publication frequency: Monthly

- 9 subject areas of science, technology and medicine

- Fair and rigorous peer-review system

- Fast publication process

- Article promotion in various social networking sites (LinkedIn, Facebook, Twitter, etc.)

- Maximum dissemination of your research work

Submit Your Paper Online: Click Here to Submit

Or Contact service@oalib.com 